\title{
Chronic treatment with myo-inositol reduces white adipose tissue accretion and improves insulin sensitivity in female mice
}

\author{
Marine L. CROZE ${ }^{1,2,3,4}$, Roxane E. VELLA ${ }^{1,2,3,4}$, Nicolas J. PILLON ${ }^{1,2,3,4}$, Hédi A. SOULA ${ }^{1,2,3,4}$, \\ Lilas HADJI ${ }^{1,2,3,4}$, Michel GUICHARDANT ${ }^{1,2,3,4}$, Christophe O. SOULAGE ${ }^{1,2,3,4}$ \\ ${ }^{1}$ Lyon university, F-69600, Oullins, France ; \\ ${ }^{2}$ INSERM, U1060, CarMeN laboratory, F-69621, Villeurbanne, France \\ ${ }^{3}$ Lyon 1 University, F-69621, Villeurbanne, France \\ ${ }^{4}$ INSA-Lyon, IMBL, F-69621, Villeurbanne, France
}

\section{Corresponding author:}

Marine L. CROZE

CarMeN, Cardiovasculaire, Métabolisme, diabétologie et Nutrition

INSERM U1060, Bâtiment IMBL,

INSA-Lyon, 20 avenue Albert EINSTEIN

F-69621 VILLEURBANNE cedex

France

Tel : +33472437235

Fax : +33472438524

E-mail : marine.croze $@$,insa-lyon.fr

Running title : Metabolic effects of myo-inositol

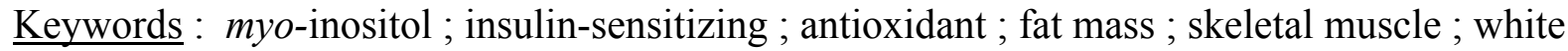
adipose tissue 


\begin{abstract}
Type 2 Diabetes is a complex disease characterized by a state of insulin resistance in peripheral tissues such as skeletal muscle, adipose tissue or liver. Some inositol isomers have been reported to possess insulin-mimetic activity, and to be efficient in lowering blood glucose level. The aim of the present study was to assess in mice the metabolic effects of a chronic treatment with myo-inositol, the most common stereoisomer of inositol. Mice given myo-inositol treatment ( 0.9 or $1.2 \mathrm{mg}^{-\mathrm{g}^{-1}}$ per day, 15 days, orally or intraperitoneally) exhibited an improved glucose tolerance due to a greater insulin sensitivity. Mice treated with myo-inositol exhibited a decreased white adipose tissue accretion $(-33 \%, \mathrm{p}<0.005)$ compared with controls. The decrease in white adipose tissue deposition was due to a decrease in adipose cell volume $(-33 \%, \mathrm{p}<0.05)$ while no change was noticed in total adipocyte number. In skeletal muscle, in vivo as well as ex vivo myo-inositol treatment increased protein kinase $\mathrm{B} /$ Akt phosphorylation under baseline and insulin stimulated conditions suggesting a synergistic action of myo-inositol treatment and insulin on proteins of the insulin signalling pathway. Myo-inositol could therefore constitute a viable nutritional strategy for the prevention and/or treatment of insulin resistance and type 2 diabetes.
\end{abstract}


$\underline{\text { Abbreviations : }}$

ANOVA, analysis of variance

AMPK, 5'-AMP activated protein kinase

AU, arbitrary unit

BMI, body mass index

BSA, bovine serum albumin

BW, body weight

DTT, dithiothreitol

EIA, enzyme immunoassay

EDTA, ethylenediaminetetraacetic acid

GLUT4, glucose transporter 4

GPI, glycosylphosphatidylinositol

GTT, glucose tolerance test

HOMA-IR, homeostasis model assessment of insulin resistance

IgG, immunoglobulin $\mathrm{G}$

IL-1, interleukin 1

IL-6, interleukin 6

IL-8, interleukin 8

IL-10, interleukin 10

IPG(s), insulin phosphoglycan(s)

IRS, insulin receptor substrate

ITT, insulin tolerance test

$\mathrm{K}_{\mathrm{ITT}}$, glucose disappearance rate during ITT

$\mathrm{KRB}$, Krebs ringer bicarbonate buffer

LD50, lethal dose $50 \%$ 
MEM, minimum essential medium

NEFA, non-esterified fatty acids

$\mathrm{PKB} / \mathrm{Akt}$, protein kinase $\mathrm{B} / \mathrm{Akt}$

PI3K, phosphoinositide-3-kinase

$\mathrm{PIP}_{2}$, phosphatidyl inositol-4,5-bisphosphate

ROS, reactive oxygen species

SDS-PAGE, sodium dodecyl sulfate polyacrylamide gel electrophoresis

sdLDL, small dense lipoproteins

TBARS, thiobarbituric acid reactive substances

TBST, Tris-Buffered Saline - Tween 20

TNF- $\alpha$, Tumor necrosis factor alpha

WAT, white adipose tissue

pWAT, parametrial WAT

rWAT, retroperitoneal WAT

scWAT, subcutaneous WAT 


\section{Introduction}

Type 2 diabetes mellitus is a complex disease characterized by a state of insulin resistance of peripheral tissues such as skeletal muscle, white adipose tissue and liver. In order to manage diabetes mellitus blood glucose must be controlled, especially in postprandial condition since its regulation implies, in this case, the actions of insulin in suppressing hepatic glucose production and triggering glucose uptake in skeletal muscle and adipose tissue. Inositol, formerly referred to as vitamin B7, stands for 1,2,3,4,5,6-cyclohexanehexol and includes nine distinct stereoisomers (named allo-, D-chiro-, L-chiro-, cis-, epi-, mисо-, mуo-, neo-, and scyllo-inositol) through epimerization in hydroxyl group configuration (see Supplementary Fig. 1). In addition to various biological functions for the treatment of diseases such as depression, panic disorder or polycystic ovary syndrome (1-5), some inositol derivatives exhibit insulin-mimetic activity, and are efficient in lowering blood glucose level. For instance, administration of $D$-chiro-inositol to diabetic rats, rhesus monkeys, mice and humans increases glucose disposal and improves insulin sensitivity (1,6-9). D-pinitol, the 3-Omethylated form of $D$-chiro-inositol, is also one of the naturally occurring inositol derivatives. D-pinitol from soybeans or Bougainvilla spectabilis leaves has also been reported to reduce blood glucose level in streptozotocin-induced diabetic rats and in patients with diabetes mellitus (10-14). D-chiro-inositol and D-pinitol are rare inositol derivatives, whereas among all the nine inositol isomers, myo-inositol is the only one to be widely distributed in tissues and foodstuffs (15). Since myo-inositol can be converted to D-chiro-inositol in insulin sensitive tissues, namely skeletal muscle, adipose tissue and liver $(7,16,17)$, myo-inositol has been mainly regarded as a nutritional source of $D$-chiro-inositol. Ortmeyer demonstrated that administration of a high dose of myo-inositol $\left(1.5 \mathrm{~g} \cdot \mathrm{kg}^{-1}\right)$ to diabetic monkeys was efficient in lowering blood glucose level (18). Recent studies demonstrated that oral administration of myo-inositol is able to improve glucose tolerance and trigger skeletal muscle GLUT-4 translocation in C57/BL6 mice, suggesting an improvement of insulin sensitivity (19). However, in vitro studies of glucose uptake on rat L6 myotubes (20) as well as well as some experiments on rodents yielded conflicting results (6). To date the effect of a chronic treatment with myo-inositol, which would be more compatible with a therapeutic-targeted strategy for diabetes mellitus prevention or care, remains to be documented. Hence, we tested in the present study, the effect of fifteen days of treatment with myo-inositol on insulin sensitivity in female CD-1 Swiss mouse. 


\section{Methods \& Materials}

\section{Chemicals and antibodies}

Myo-inositol, was purchased from Sigma Aldrich, (Saint Quentin Fallavier, France), recombinant Human insulin (100 UI/ml, Actrapid $\left.{ }^{\circledR}\right)$ was from Novo Nordisk, (La Défense, France). Anti-Phospho-Akt 1/2/3 rabbit IgG (7985R) and anti-Akt 1/2/3 rabbit IgG (8312) antibodies were purchased from Santa Cruz Biotechnology (Santa Cruz, Heidelberg, Germany), anti-tubulin mouse IgG antibody was from Sigma Aldrich, anti-mouse IgG and anti-rabbit IgG antibodies were from BioRad (Marnes-la-Coquette, France). Super Signal ${ }^{\circledR}$ West Pico Chemiluminescent Substrate and Restore ${ }^{\mathrm{TM}}$ Western Blot Stripping Buffer were obtained from Thermo Scientific (Perbio, Brebières, France). Other chemicals were obtained from Sigma Aldrich when no origin is specified.

\section{Animals}

Female CD-1 Swiss mice (30-35g) were purchased from Janvier SA (Le Genest-Saint-Isle, France) and housed in an air-conditioned room with a controlled environment of $21 \pm 0.5^{\circ} \mathrm{C}$ and $60-70 \%$ humidity, under a $12 \mathrm{~h}$ light/dark cycle (light on from 07:00h to 19:00h) with free access to food $(13,4 \mathrm{~kJ} / \mathrm{g}, 65 \%$ carbohydrates, $11 \%$ fat, $24 \%$ proteins (w/w), AO3, SAFE, Augy, France) and water. All experiments were carried out according to the guidelines laid down by the French Ministère de l'Agriculture ( ${ }^{\circ}$ 87-848) and the E.U. Council Directive for the Care and Use of Laboratory Animals of November $24^{\text {th }}, 1986$ (86/609/EEC).

\section{Myo-inositol treatment}

Sixty mice were randomly assigned to receive daily intraperitoneal injection of either a saline

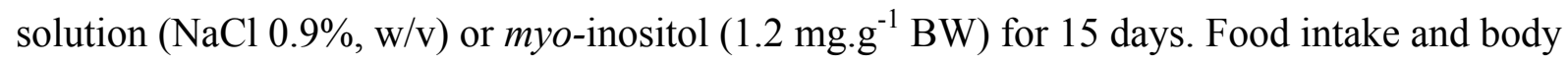
weight were measured twice weekly. Food consumption was calculated as the difference between the amount given and that removed from the cage. A second set of mice $(n=20)$ was given myo-inositol in drinking water $\left(6 \mathrm{~g} . \mathrm{L}^{-1}\right)$ for 15 days. Water consumption was measured to assess daily myo-inositol intake.

\section{Metabolic challenges}

Glucose tolerance test: After an overnight fast, animals were injected intraperitoneally with 1 g. $\mathrm{kg}^{-1}$ body weight of D-glucose in sterile water. Blood glucose was measured before and $15,30,60$ and 90 min after injection. On an independent group of animals $(n=5), 200 \mu \mathrm{L}$ of 
blood were collected by retro-orbital sinus puncture from each mouse into a heparinized microcentrifuge tube, $30 \mathrm{~min}$ after glucose load in order to measure plasma insulin level at the hyperglycaemic phase of the test. Blood was centrifuged 2 min at $3500 \mathrm{~g}\left(4^{\circ} \mathrm{C}\right)$ to prepare plasma. Plasma samples were snap frozen in liquid nitrogen and stored at $-20^{\circ} \mathrm{C}$ until insulin assay.

Insulin tolerance test: After an overnight fast, animals were injected intraperitoneally with 0.30 UI.kg ${ }^{-1} \mathrm{BW}$ of recombinant human insulin. Blood glucose was measured before and 15 , 30, 60 and $120 \mathrm{~min}$ after insulin injection. The glucose disappearance rate for ITT $\left(\mathrm{K}_{\mathrm{ITT}}\right.$; $\% \cdot \min ^{-1}$ ) was calculated using the formula given by Lundbeak (1962) (21): $\mathrm{K}_{\text {ITT }}=0.693 \times$ $100 / t_{1 / 2}$ where $t_{1 / 2}$ was calculated from the slope of the plasma glucose concentration, considering an exponential decrement of glucose concentration during the 40 min after insulin administration (22).

\section{Insulin secretion test: L-arginine induced insulin secretion.}

After an overnight fast, animals were injected intraperitoneally with 1 g.kg ${ }^{-1}$ BW of Larginine in saline and blood was withdrawn at 0,2 and 5 min after injection in heparinized microtubes. Blood was centrifuged $2 \mathrm{~min}$ at $3500 \mathrm{~g}\left(4^{\circ} \mathrm{C}\right)$ to prepare plasma. Plasma samples were snap frozen in liquid nitrogen and stored at $-20^{\circ} \mathrm{C}$ until insulin assay.

\section{Sacrifice and tissue dissection}

The body weight and body length were measured and mice were then sacrificed by cervical dislocation. Blood $(750 \mu \mathrm{L})$ was collected by heart puncture on heparinized tube, centrifuged $2 \mathrm{~min}$ at $3500 \mathrm{~g}$ to prepare plasma. Plasma samples were snap frozen in liquid nitrogen and stored at $-80^{\circ} \mathrm{C}$ until analysis. Liver, heart, kidneys, tibialis and gastrocnemius muscles, parametrial, retroperitoneal and subcutaneous inguinal white adipose tissue (WAT) were dissected out according to anatomical landmarks, weighed to the nearest milligram, snap frozen in liquid nitrogen and stored at $-20^{\circ} \mathrm{C}$.

\section{Cellularity study: Measurement of adipocyte size and number}

Preparation of adipose tissue for determination of cell size was performed essentially as described by Etherton, Thompson \& Allen (1977) (23). Briefly, 30-40 mg of parametrial WAT were immediately fixed in osmium tetroxide and incubated at room temperature for $96 \mathrm{~h}$ and then adipose cell size was determined by a Beckman Coulter Multisizer IV with a $400 \mu \mathrm{m}$ aperture. The range of cell sizes that can effectively be measured using this aperture is 20-240 $\mu \mathrm{m}$. The instrument was set to count 1,000 particles, and the fixed-cell suspension was diluted 
so that coincident counting was $<10 \%$. Cell-size distributions were drawn from measurement of at least 12,000 cell diameters per animal. DNA content in parametrial WAT was measured, after delipidation of the samples, by a standard fluorimetric method using bisbenzimide and calf thymus DNA as standard (24).

\section{Isolation of adipocytes}

Five mice of each group were killed by cervical dislocation, parametrial and retroperitoneal fat pads were dissected out, pooled and the adipocytes were isolated. Adipose tissue was weighed, minced and digested in $7 \mathrm{ml}$ of Krebs Ringer Bicarbonate (KRB, pH 7.40) buffer containing $6 \mathrm{mM}$ glucose, $1 \%(\mathrm{w} / \mathrm{v})$ fatty acid-free bovine serum albumin (BSA) and 1.5 mg. $\mathrm{ml}^{-1}$ collagenase (type II, C6885, Sigma Aldrich). The vial was shaken (40 cycles.min ${ }^{-1}$ ) at $37^{\circ} \mathrm{C}$ for $60 \mathrm{~min}$. The resulting cell suspension was filtered through a nylon mesh $(250 \mu \mathrm{m})$ and washed three times with KRB buffer containing 4\% fatty acid-free BSA. Then adipocytes were resuspended in KRB containing $4 \%$ fatty acid-free BSA and counted in a hemacytometer.

\section{Lipogenesis assay}

Lipogenesis was measured in mouse isolated adipocytes as the incorporation of $\left[{ }^{14} \mathrm{C}\right]$-acetate into total lipids as previously described (25). Briefly, aliquots $(100 \mu 1)$ of cell suspension were incubated in MEM medium containing $1 \%$ fatty acid-free BSA and $1 \mu \mathrm{Ci}$ of $\left[{ }^{14} \mathrm{C}\right]$-acetate for $4 \mathrm{~h}$ at $37^{\circ} \mathrm{C}$ with gentle shaking $\left(40\right.$ cycles. $\left.\mathrm{min}^{-1}\right)$. Total lipids were extracted using Dole's extraction fluid (isopropanol/heptane $/ \mathrm{H}_{2} \mathrm{SO}_{4} 1 \mathrm{~N}, 40 / 10 / 1, \mathrm{v} / \mathrm{v} / \mathrm{v}$ ) and $\left[{ }^{14} \mathrm{C}\right]$ was detected by liquid scintillation counting.

\section{Lipolysis}

Aliquots of the cell suspension $(100 \mu 1)$ were distributed in 2 ml-polystyrene vials containing KRB buffer $4 \%$ BSA with or without isoproterenol hydrochloride $(5 \mu \mathrm{M})$. Adipocytes were incubated at $37^{\circ} \mathrm{C}$ with gentle shaking $\left(40\right.$ cycles. $\left.\min ^{-1}\right)$ for one hour. The reaction was stopped by placing vials on melting ice. The floating adipocytes were discarded by aspiration and lipolysis was quantified by measuring the release of extracellular glycerol using a kit (Glycerol assay, R-Biopharm, Saint Didier aux Monts d'Or, France).

\section{Biochemical measurements}

Fasting and non-fasting blood glucose levels were measured with a glucometer (Accu Check 
Performa, Roche diagnostic, Meylan, France). The plasma insulin level was determined with mouse insulin EIA kit (SpiBio, Montigny-le-Bretonneux, France) according to the manufacturer's instructions. The homeostasis model assessment of insulin resistance (HOMA-IR) was calculated using glucose and insulin concentrations obtained after $16 \mathrm{~h}$ of food withdrawal, using the following formula: fasting blood glucose $\left(\mathrm{mg} \cdot \mathrm{dl}^{-1}\right) \times$ fasting insulin $\left(\mu \mathrm{U} \cdot \mathrm{ml}^{-1}\right) / 405$. Plasma total cholesterol, triacylglycerols and non-esterified fatty acid (NEFA) levels were measured with the following commercial kits, Cholesterol RTU (bioMérieux, Marcy-l'Etoile, France), Triglyceride PAP (bioMérieux) and NEFA-C (WAKO, Sobioda, Montbonnot, France) according to manufacturer's recommendations. Plasma adiponectin and leptin concentrations were determined with enzymo immuno assays (Cayman Chemicals, distributed by SpiBio) according to the manufacturer's guidelines. All assays were performed at least in duplicates. The muscle and hepatic lipids were extracted using the procedure developed by Folch (26) using Chloroform-Methanol $(2: 1, \mathrm{v} / \mathrm{v})$ and total lipid content was estimated gravimetrically.

\section{Plasma total antioxidant activity}

The total plasma antioxidant activity was measured as described by Koracevic et al. (2001) (27). Briefly, the assay measured the capacity of $10 \mu \mathrm{l}$ of plasma to inhibit the production of thiobarbituric acid reactive substances (TBARS) from sodium benzoate under the influence of the free oxygen radicals derived from Fenton's reaction. A solution of $1 \mathrm{mM}$ uric acid was used as standard and results were expressed as mM equivalent uric acid.

\section{In vivo and ex vivo insulin stimulation}

In vivo insulin stimulation: To further explore insulin signalling in skeletal muscle, control and myo-inositol mice were randomly assigned to receive either saline or insulin $\left(0.75\right.$ UI. $\mathrm{kg}^{-1}$ BW, i.p.) 30 min before sacrifice. Mice were killed by cervical dislocation, gastrocnemius muscle was rapidly dissected out, blotted dry and snap frozen in liquid nitrogen.

Ex vivo insulin stimulation: To decipher whether myo-inositol was able to directly act on muscle, we performed an in vitro incubation of skeletal muscle with myo-inositol and in vitro insulin stimulation. Mice were killed by cervical dislocation, gastrocnemius were rapidly dissected out bilaterally and chopped into small pieces with a scalpel. Muscle pieces were incubated in $3 \mathrm{ml}$ of MEM medium containing insulin $(100 \mathrm{nM})$ and $m y o$-inositol $(1 \mathrm{mM}), D$ chiro-inositol $(1 \mathrm{mM})$ or mannitol $(1 \mathrm{mM})$ as a control. Muscles were incubated for $15 \mathrm{~min}$ at $37^{\circ} \mathrm{C}$, blotted dry and snap frozen in liquid nitrogen. 


\section{Immunoblotting - insulin induced phosphorylation of PKB/Akt in skeletal muscle}

Gastrocnemius was homogenised in standard lysis buffer $(20 \mathrm{mM}$ Tris- $\mathrm{HCl}, 138 \mathrm{mM} \mathrm{NaCl}$, 2.7 $\mathrm{mM} \mathrm{KCl}, 1 \mathrm{mM} \mathrm{MgCl} 2,5 \%$ Glycerol and 1\% Nonidet P40) supplemented with protease and phosphatase inhibitors ( $5 \mathrm{mM}$ EDTA, $1 \mathrm{mM} \mathrm{Na}_{3} \mathrm{VO}_{4}, 20 \mathrm{mM} \mathrm{NaF}, 1 \mathrm{mM}$ DTT, Protein inhibitor cocktail, Sigma Aldrich). $60 \mu \mathrm{g}$ of tissue lysate soluble fraction proteins were boiled in Laemmli buffer and separated by $10 \%$ sodium dodecyl sulfate - polyacrylamide gel electrophoresis (SDS-PAGE). After transfer to a nitrocellulose membrane, and aspecific sites blockage with Bovine Serum Albumin (BSA) 5\% in TBST (10 mM Tris- $\mathrm{HCl}$ at $\mathrm{pH} 8.0,150$ $\mathrm{mM} \mathrm{NaCl}$ and $0.05 \%$ Tween-20), Akt activating phosphorylation on serine was detected using primary anti-phospho(Ser 473)-Akt(1/2/3) antibody (1/1000e in TBST 3\% BSA Overnight, $4^{\circ} \mathrm{C}$ ) and then secondary antibody (anti-rabbit, 1/10 000e TBST $-1 \mathrm{~h}$, room temperature) conjugated with horseradish peroxidase. Membranes were processed for chemiluminescence and proteins were quantitated by densitometry using Quantity One software (BioRad). In order to normalise for equal protein loading, membranes were stripped and re-blotted with anti total Akt(1/2/3) antibody and then anti- $\alpha$-tubulin antibody.

\section{Statistics}

Data are expressed as means \pm SD $(n<4)$ or means \pm SE $(n \geq 4)$. Data were analyzed using GraphPad Prism v5.0 software (GraphPad software, La Jolla, USA). Results of GTT, ITT and arginine tests were compared by two-way analysis of variance (time, treatment) followed when appropriated by posthoc Fisher PLSD tests. Simple comparisons were performed using Student's $t$-test. When appropriated, Welch's correction for inequality of variances was applied. Regression analyses were performed using linear regression. Adipocyte volume distribution curves were compared with the Kolmogorov-Smirnov two-sample test using " $\mathrm{R}$ " software (www.R-project.org). Differences were considered significant at the $\mathrm{p}<0.05$ level.

\section{Results}

Chronic treatment with myo-inositol reduced white adipose tissue accretion

To evaluate its in vivo activity, mice were given daily injection of myo-inositol $\left(1.2 \mathrm{mg} . \mathrm{g}^{-1}\right.$ per day) or saline for 15 days. Biometric data for each group are shown in Table 1. Body weights of myo-inositol-treated animals were not significantly altered compared with salinetreated animals. Neither food intake nor water intake were different between saline- and myo- 
inositol-treated animals. The mean daily food intake was $48.1 \pm 0.9$ and $50.5 \pm 3.8 \mathrm{~kJ}$ per $24 \mathrm{~h}$ for mice treated with saline and myo-inositol, respectively $(\mathrm{n}=14, \mathrm{p}=0.573)$. Organs (liver, heart, kidneys and muscles) weights, taken as representative of lean mass, were not different between the two groups but myo-inositol treatment significantly reduced adiposity as evidenced by a lower adiposity index (Lee index $n=14, p<0.05)$ and a significantly reduced fat mass accretion $(-33 \%, \mathrm{n}=14, \mathrm{p}<0.005)$. Myo-inositol treatment significantly reduced accretion of intra-abdominal fat pad, that is, retroperitoneal and parametrial fat pads while no effect was noticed on sub-cutaneous fat pad, that is, inguinal fat pad (Table 1). Indeed, parametrial and retroperitoneal WAT masses were reduced by $38 \%$ in myo-inositol treated animals, while subcutaneous WAT mass remained unaltered. Of note, the fat mass loss was not associated with ectopic redistribution of lipids in liver or skeletal muscles as evidenced by the measurement of tissues lipid contents (Table 2).

\section{Effect of chronic treatment with myo-inositol on plasma metabolites}

The plasma metabolites levels for each group are shown in Table 2. The plasma levels of triacylglycerols or cholesterol were not affected by myo-inositol treatment. However, plasma level of non-esterified fatty acids was sharply reduced in myo-inositol mice $(-37 \%, \mathrm{n}=14-16$, $\mathrm{p}<0.001)$. Fasting blood glucose level was not significantly different between the two groups $(\mathrm{n}=14, \mathrm{p}=0.41)$ while fed plasma glucose level of myo-inositol mice was significantly lower than that of control mice $(-10 \%, \mathrm{n}=14, \mathrm{p}<0.05)$. The homeostasis model assessment of insulin resistance (HOMA-IR) was calculated as a clinical parameter for the insulin resistance, from the values of blood glucose and insulin plasma levels. The HOMA-IR index for myo-inositol group was similar to that of control group $(n=6, p=0.89)$. In good agreement with the reduction of fat accretion observed in myo-inositol mice, we noticed a significant decrease in plasma leptin concentration $(-63 \%, \mathrm{n}=9-10, \mathrm{p}<0.05)$. Plasma leptin concentration was negatively correlated with total white adipose tissue mass $\left(n=19, r^{2}=0.741, p<0.0001\right.$, see supplementary Fig. 2). In contrast, no difference in plasma adiponectin level was noticed between the two groups (Table 2). Myo-inositol treated mice exhibited a higher total antioxidant plasma activity than control mice $(+46 \%, \mathrm{n}=9-10, \mathrm{p}<0.005$, Table 2$)$.

\section{Chronic treatment with myo-inositol improved glucose tolerance and insulin sensitivity}

To get an insight into glucose homeostasis, glucose, insulin and arginine challenges were performed in myo-inositol and saline-treated mice. Glucose tolerance test showed that the glucose load induced a marked and transient rise in blood glucose level with a complete 
normalisation 90 min after injection (Fig. 1A). Under the same conditions, myo-inositol mice exhibited a lower blood glucose level than control mice at 15 and $30 \mathrm{~min}$ after glucose injection ( $n=10, p<0.05$ and $\mathrm{p}<0.001$, respectively), suggesting a better glucose tolerance. Consequently, the area under the curve of glycaemia was significantly lower in the myoinositol mice $\left(11660 \pm 329 \mathrm{mg} \cdot \mathrm{dl}^{-1} \cdot \mathrm{min}^{-1}\right)$ compared to control mice $\left(14420 \pm 873 \mathrm{mg} . \mathrm{dl}^{-}\right.$ $\left.{ }^{1} \cdot \min ^{-1}\right)$ indicating a faster glucose disposal $(\mathrm{n}=10, \mathrm{p}<0.05)$. The better glucose tolerance may be attributed to either increased peripheral insulin sensitivity or improved glucose-stimulated insulin secretion. To determine whether the observed glucose tolerance was the result of greater insulin secretion, insulin was assayed during the glucose tolerance test. Baseline plasma insulin levels were not different, but insulin secretion in response to hyperglycaemia (i.e. 30 min after glucose injection) was significantly lower for the myo-inositol group (Fig. 1B, $\mathrm{n}=7, \mathrm{p}<0.005$ ) suggesting a better insulin sensitivity rather than a greater insulin secretion. To further measure the in vivo insulin response of myo-inositol treated mice, we performed administration of the non-glucose secretagogue arginine. The acute insulin response ( 2 min after arginine injection) was similar in the two groups (Fig. 1C) excluding difference in insulin secretion capacity. The results of the insulin tolerance test (ITT) are shown in Fig. 1D. Insulin administration $\left(0.3 \mathrm{UI} . \mathrm{kg}^{-1}\right)$ triggered a significantly $(\mathrm{p}<0.01)$ larger hypoglycaemic response in myo-inositol mice (-45\% in blood glucose level) compared to control mice $(-25 \%)$. The glucose disappearance rate $\left(\mathrm{K}_{\mathrm{ITT}}\right)$ was two-fold higher in myoinositol than in control mice $\left(10.3 \pm 1.2\right.$ versus $\left.5.8 \pm 1.6 \% \cdot \mathrm{min}^{-1}, \mathrm{n}=10, \mathrm{p}<0.05\right)$. Taken together, the results of the metabolic challenges indicated a better glucose tolerance due to a better insulin sensitivity of myo-inositol treated mice. Interestingly, the glucose disappearance rate $\left(\mathrm{K}_{\mathrm{ITT}}\right)$ that reflects insulin sensitivity, was negatively correlated with central fat mass (Fig. 2, $\mathrm{r}=-0.718, \mathrm{p}<0.002$ ). Hence, the reduction in fat mass accretion could be a major determinant of the long term insulin-sensitizing effect of myo-inositol treatment.

\section{Chronic treatment with myo-inositol potentiated insulin signalling in skeletal muscle}

To get an insight into insulin signalling pathway, phosphorylation of PKB/Akt was explored in skeletal muscle after insulin stimulation in vivo. Results from immunoblotting (Fig. 3A) showed a twofold increase in phosphorylation level of PKB/Akt in the gastrocnemius muscle of control mice in response to insulin $(+66 \%, \mathrm{p}<0.05)$. Myo-inositol treatment increased $\mathrm{PKB} /$ Akt phosphorylation under baseline conditions $(+66 \%$ from unstimulated control, $\mathrm{p}<0.05)$ as well as in response to insulin $(+166 \%$ from unstimulated control, $\mathrm{p}<0.05)$ suggesting an additive effect of insulin and myo-inositol. Some authors $(19,28)$ suggested that 
in vivo, myo-inositol is metabolically converted into other inositol isomers (especially $D$ chiro-inositol) which could mediate its effects on glucose metabolism. To challenge this view, mouse isolated gastrocnemius were incubated in presence of $1 \mathrm{mM}$ of myo-inositol, D-chiroinositol or mannitol (as an osmotic control) with or without insulin (100nM). Myo-inositol but not D-chiro-inositol potentiated insulin induced PKB/Akt phosphorylation on Serine ${ }^{473}$ in baseline as well as insulin-stimulated conditions (Fig. 3B) suggesting a direct action of myoinositol on muscle or its conversion in situ to an active metabolite.

\section{Myo-inositol is active when orally administered}

We tested the effect of 15 days of oral administration of myo-inositol on fat accretion in mice (Table 3). The mean daily intake of myo-inositol was $0.90 \pm 0.04 \mathrm{mg} . \mathrm{g}^{-1}$ per day. Oral administration of myo-inositol decreased intra-peritoneal fat accretion (Table 3). The 2-way ANOVA indicated a main effect of treatment $(p<0.05)$, a main effect of WAT site $(p<0.001)$, as well as a treatment $\times$ WAT site interaction $(\mathrm{p}<0.05)$. Indeed, parametrial WAT, retroperitoneal WAT and subcutaneous WAT weights were decreased by $34 \%(\mathrm{p}<0.05), 33 \%$ $(\mathrm{p}<0.05)$ and $47 \%(\mathrm{p}<0.01)$, respectively in myo-inositol animals while no difference was noticed for muscle or organ weights. Myo-inositol $0.9 \mathrm{mg} . \mathrm{g}^{-1}$ per day orally significantly reduced fat accretion in mice showing that myo-inositol was active after oral administration as well (Fig. 4A). Myo-inositol treated mice exhibited a lower white adipose tissue accretion relative to their body mass than saline treated mice (Fig. 4B). Indeed, the slope of the linear regression of fat accretion in saline treated mice was $\left(226.2 \pm 36.6 \mathrm{mg} \mathrm{WAT} / \mathrm{g} \mathrm{BW}, \mathrm{r}^{2}=0.65\right)$ while it was $\left(128.6 \pm 30.5 \mathrm{mg} \mathrm{WAT} / \mathrm{g} \mathrm{BW}, \mathrm{r}^{2}=0.45\right)$ in $m y o$-inositol treated mice (significant difference between the slopes, $\mathrm{p}=0.04, \mathrm{n}=24$ in each group). To analyze whether changes in WAT accretion resulted from a reduction in the number of adipocytes, a decreased triglyceride accumulation in adipocytes or both, we performed a cytological analysis of parametrial WAT pad. The distribution frequencies of adipocyte volume for saline or myoinositol treated mice are shown in Fig. 4C,D. A significant shift leftward was observed in frequency distribution of adipocyte volumes of mice treated with myo-inositol compared with control animals. The cellular characteristics of parametrial WAT in control and myo-inositolfed mice are shown in Table 4. The reduction of WAT accretion resulted from a reduction in the volume of adipocytes (i.e. hypotrophia) (see supplementary Fig. 3) rather than from a decrease in the total number of adipocytes per fat pad (i.e. hypoplasia). Indeed, mean adipocyte diameter was reduced by $13 \%$ in myo-inositol treated mice $(n=9-10, p<0.05)$ 
resulting in a $33 \%$ decrease in adipose cell volume $(n=8-10, p<0.01)$. The total number of adipocytes per parametrial fat pad, calculated from cell weight, failed to show any difference in the total number of adipocytes between myo-inositol and control mice. As DNA amount reflects adipose cell number more accurately than any other method, we performed DNA assay in parametrial WAT. No difference was observed in DNA content, excluding a decrease in the total number of adipocytes in pWAT pads. To get an insight into the mechanisms of myo-inositol action on adipose cells, we measured both the lipolytic response to catecholamines and de novo lipogenesis. To this end, mice were fed for 15 days with myoinositol in drinking water $\left(6 \mathrm{~g} . \mathrm{L}^{-1}\right)$ and lipogenesis and lipolytic activities were measured on adipocytes isolated from parametrial fat pad of control and myo-inositol fed mice (Fig. 4E,F). Lipolysis and lipogenesis measured on isolated adipose cells failed to show any difference between the 2 groups.

\section{Discussion}

In the present study, myo-inositol was evaluated for its putative effects on glucose homeostasis and insulin sensitivity in female mice. To this end, female CD1 mice were given daily injection $\left(1.2 \mathrm{mg} \mathrm{kg}^{-1}\right)$ or were fed with myo-inositol $\left(0.9 \mathrm{mg} \cdot \mathrm{kg}^{-1}\right)$ for 15 days. Our results demonstrate that intraperitoneally as well as orally administered myo-inositol improved glucose tolerance, enhanced insulin sensitivity and decreased adipose tissue accretion in mice. Of note myo-inositol treatment did not promote insulin secretion by pancreatic beta-cells, as evidenced by arginine challenge. Various inositol derivatives, such as D-chiro-inositol $(9,29)$ and D-pinitol $(11,13)$ exhibited an insulin-mimetic activity, and were efficient in lowering blood glucose level. However, they remained rare compounds in contrast with myo-inositol which is the most common stereoisomer of inositol. The primary naturally occurring sources of myo-inositol in food are inositol hexaphosphate (also referred to as phytic acid, which is widely found in fruits, vegetables, cereals, nuts and beans) and inositolcontaining phospholipids (i.e. phosphatidyl-inositol) from animal and plant sources. In humans, myo-inositol has been successfully used in the treatment of psychiatric disorders such as depression, obsessive-compulsive disorder or panic attacks, as well as in the treatment of polycystic ovary syndrome and diabetic neuropathy (2,3,30-32). Ortmeyer et al. demonstrated that administration of myo-inositol to type 2 diabetic rhesus monkeys was efficient to manage blood glucose level (18). Recently, Dang et al. reported that acute oral administration of myo-inositol lowers plasma glucose after an oral GTT and induces GLUT4 
translocation in mice skeletal muscle (19). However some in vitro studies and experiments on rodent yielded conflicting results. Indeed, in contrast to many inositol stereoisomers (including D-chiro-inositol) myo-inositol failed to stimulate glucose uptake in L6 muscle cells (20). Low doses $\left(10 \mu \mathrm{g} \cdot \mathrm{g}^{-1} \mathrm{BW}\right)$ of myo-inositol were reported to be inefficient for the regulation of plasma glucose level in rat with streptozotocin-induced diabetes contrary to low doses of D-chiro-inositol (6). Human studies also yielded conflicting results regarding its potency to improve glucose metabolism. Maeba et al. (2008) (33) showed that a myo-inositol chronic treatment decreased atherogenic cholesterol level (especially sdLDL) in human hyperlipidemic subjects (with or without metabolic syndrome) but a positive effect on glucose metabolism was only observed in the sub-group of hyperlipidemic subjects with metabolic syndrome. In a recent study, Corrado et al. (2011) (34) demonstrated that myo-inositol improved HOMA-IR in women with gestational diabetes.

We demonstrated that myo-inositol potentiated insulin action in vivo as well as in vitro. According to the result of the immunoblotting on PKB-Akt in mice gastrocnemius muscle, it can be presumed that myo-inositol treatment improves insulin sensitivity via the induction of the intracellular insulin signalling cascade at the level of this protein (PKB-Akt) and possibly even upstream in the cascade, at the level of the PhosphoInositide-3-Kinase (PI3K), whose substrate $\mathrm{PIP}_{2}$ is produced from myo-inositol precursors. These results are in good agreement with data from Dang et al. (19) who demonstrated that myo-inositol increased GLUT-4 translocation to plasma membrane at a basal level (i.e. in absence of insulin stimulation). Our results indicated that the increased translocation of GLUT-4 to plasma membrane could be mediated through the canonical PI3K/Akt pathway. Further studies are however needed to decipher the exact mechanism of action of myo-inositol in muscle cells. Many authors postulated that myo-inositol acted on glucose homeostasis through its conversion to an active metabolite $(19,34)$. Some studies $(19,28,35)$ suggest that myo-inositol is metabolically converted into other inositol isomers or derivatives in vivo, in particular in D-chiro-inositol (DCI) or inositol phosphoglycans (IPGs). Indeed, D-chiro-inositol was found to be directly active in vitro to stimulate GLUT-4 translocation to the membrane in muscle cells, while myo-inositol was only active in vivo in mouse skeletal muscle $(19,20)$. Moreover myo-inositol can be converted to D-chiro-inositol by a specific epimerase with a conversion rate of $7.6 \%$ and $8.8 \%$ in blood and muscle respectively (16) it is then possible that myo-inositol is active on glucose metabolism through its conversion to D-chiro-inositol. However, the underlying mechanisms of this insulin-like activity of D-chiro-inositol remain elusive. It has been 
presumed that D-chiro-inositol activates $\mathrm{PI} 3 \mathrm{~K}$ and/or 5'AMP-activated protein kinase (AMPK) to stimulate GLUT-4 translocation (19). D-chiro-inositol increases skeletal muscle glycogen synthase activity and decreases glycogen phoshorylase activity during a euglycemic hyperinsulinemic clamp in rhesus monkeys (36). Besides, D-chiro-inositol was originally discovered as a component of an inositol phosphoglycan (IPG), and some data suggest that inositol phosphoglycans are second messengers of insulin action, released from GPI membrane precursors in response to insulin $(28,35),(37)$. IPGs are able to mimic many of the insulin actions including stimulation of lipogenesis, glycogen synthesis and glucose uptake. All the natural IPGs contain a terminal inositol and both chiro- and myo-inositol isomers were found $(7,28)$. Hence a part of the chronic myo-inositol treatment effect on insulin sensitivity could be due to the enhanced production of IPGs containing myo-inositol. Larner et al. proposed a mechanism of action for the IPGs and a new insulin signaling model including those second messengers $(7,28)$. In this new model, a surrogate pathway for insulin signal transduction runs in parallel of the conventional IRS/PI3K/PKB-Akt pathway that leads to glucose uptake. This second pathway leads to glycogen synthase and/or pyruvate deshydrogenase activation, and so to the enhanced non-oxidative and/or oxidative glucose disposal. Recent data challenged this view since over a large collection of synthetic IPGs, none were found to be insulin mimetic (38). The existence and the physiological relevance of these IPGs remain therefore questionable. In order to challenge the hypothesis of a metabolic conversion of myo-inositol to D-chiro-inositol in vivo, we tested the effects of myo-inositol and D-chiro-inositol on Protein Kinase B activation state in mouse isolated gastrocnemius muscles, with or without insulin stimulation (Fig. 3B). According to our result however, myoinositol but not D-chiro-inositol potentiated insulin induced $\mathrm{PKB} / \mathrm{Akt}$ phosphorylation on Serine $^{473}$. Hence myo-inositol effect on PKB/Akt activation in vivo (Fig. 3A) seems to be independent of its metabolic conversion to D-chiro-inositol.

Insulin sensitivity is strongly related to body fat content even within subjects with normal BMI (39). Since obesity has generally been regarded as an important contributory factor in peripheral insulin resistance, the question arises as to whether the lower adiposity of the myoinositol mice is the primary factor responsible for the observed changes in insulin sensitivity noted in the present study (Fig. 5). Indeed, increased visceral fat is associated with decreases in peripheral and hepatic insulin sensitivity (40-42) and in good agreement, surgical extraction of visceral fat has been shown to reverse insulin resistance in young obese and old male rodents (43). We noticed in the present study a strong correlation between insulin sensitivity 
(estimated through $\mathrm{K}_{\text {ITT }}$ index) and fat mass suggesting that fat mass loss could be a determining factor of myo-inositol insulin-sensitizing action in the long term, in addition to its action on insulin signalling in muscle. The exact mechanism involved in fat mass loss remains however to be defined. Adipose tissue is now recognized as a major secretory tissue (44) releasing into blood flow many hormones and cytokines (named adipokines) that affect metabolism. Several adipokines have been involved in insulin resistance (resistin, TNF- $\alpha$, IL6,...) or as insulin sensitizing factor (adiponectin). However, myo-inositol treatment was not associated with an increase in plasma adiponectin level excluding a role for adiponectin in its insulin sensitizing effect. Hypertrophy of white adipose tissue exacerbates the secretion of pro-inflammatory cytokines, such as IL-6, IL-1, IL-8, TNF- $\alpha$ while regulatory cytokines, such as IL-10, are decreased. Accumulated fat is therefore associated with low-grade inflammation that could contribute to metabolic syndrome and insulin resistance associated with overweight $(45,46)$. We noticed a significant decrease in plasma NEFA levels in myo-inositol mice (see supplementary Fig. 4). The adverse effects of increased NEFA availability on insulin sensitivity are well known from the works of Randle et al. (48) showing that increased availability of fatty acids decreases glucose utilization in muscle. NEFA are also a potent stimulus to hepatic glucose production (47), (48). The decrease of plasma NEFA level could therefore underlie the improvement of insulin sensitivity. Furukawa et al. (2004) reported that increased oxidative stress in accumulated fat was an important pathogenic mechanism of obesity-associated metabolic syndrome (49). Fat accumulation correlated with systemic oxidative stress in both humans and mice. Production of ROS was selectively increased in adipose tissue of obese mice, associated with a blunted expression of antioxidative enzymes. The decrease in WAT mass described in the present study could contribute to the better redox status of myo-inositol mice as evidenced by the measurement of plasma antioxidant activity. This effect can contribute to the improvement of insulin sensitivity as does most antioxidant substances (50-54). Of note, a recent study on Jian carp (55) confirmed the antioxidant potency of chronic myo-inositol treatment, showing that myo-inositol presupplementation prevented copper-induced oxidative damage in vivo and ex vivo on intestine, presumably through the induction of key antioxidant enzymes. Some studies also reported a direct antioxidant activity of phosphorylated forms of myo-inositol (i.e. phytic acid) via iron III chelation (56), and of derivatives such as D-chiro-inositol and D-pinitol, through the quenching of superoxide anion and hydroxyl radical (57). 
As a conclusion, this study shows that a chronic treatment with myo-inositol 1) improves glucose tolerance in mouse by increasing insulin sensitivity 2) potentiates insulin action on the conventional PI3K/Akt insulin signalling pathway 3 ) reduces fat mass accretion 4) improves antioxidant status Further studies are however required to decipher the mechanisms underlying those effects of myo-inositol. Myo-inositol only exhibited an extremely low toxicity as its oral LD50 in mouse is $10000 \mathrm{mg} \cdot \mathrm{kg}^{-1}$ (Myo-inositol Material Safety Data Sheet). In Human, no serious adverse effects were observed in doses up to 18 g.day ${ }^{-1}$ for up to 3 months. Only minor and non life threatening gastrointestinal adverse events were reported with daily intake of high doses of myo-inositol (up to 30 g.day $^{-1}$ ) (58). Myoinositol could therefore constitute a viable and safe nutritional strategy to delay or prevent insulin-resistance development and/or type 2 diabetes onset.

\section{Acknowledgments}

This work was supported by INSERM and INSA-Lyon. M.L. CROZE, R.E. VELLA and L. HADJI were recipient for grants from the French "Ministère de la Recherche et de la Technologie". The authors gratefully acknowledge Bertrand CARE (INSERM U1060 CarMeN \& LIRIS UMR 5205 CNRS / INSA-Lyon) for statistical assistance.

\section{Disclosure}

The authors declare no conflict of interest. 


\section{References}

1. Nestler JE, Jakubowicz DJ, Reamer P, Gunn RD, Allan G. Ovulatory and metabolic effects of D-chiro-inositol in the polycystic ovary syndrome. N. Engl. J. Med. 1999;340(17):1314-20.

2. Benjamin J, Agam G, Levine J, Bersudsky Y, Kofman O, Belmaker RH. Inositol treatment in psychiatry. Psychopharmacol Bull. 1995;31(1):167-75.

3. Benjamin J, Levine J, Fux M, Aviv A, Levy D, Belmaker RH. Double-blind, placebocontrolled, crossover trial of inositol treatment for panic disorder. Am J Psychiatry. 1995;152(7):1084-6.

4. Iuorno MJ, Jakubowicz DJ, Baillargeon J-P, Dillon P, Gunn RD, Allan G, et al. Effects of d-chiro-inositol in lean women with the polycystic ovary syndrome. Endocr Pract. 2002;8(6):417-23.

5. McLaurin J, Golomb R, Jurewicz A, Antel JP, Fraser PE. Inositol stereoisomers stabilize an oligomeric aggregate of Alzheimer amyloid beta peptide and inhibit abeta induced toxicity. J. Biol. Chem. 2000;275(24):18495-502.

6. Ortmeyer HK, Huang LC, Zhang L, Hansen BC, Larner J. Chiroinositol deficiency and insulin resistance. II. Acute effects of D-chiroinositol administration in streptozotocindiabetic rats, normal rats given a glucose load, and spontaneously insulin-resistant rhesus monkeys. Endocrinology. 1993;132(2):646-51.

7. Larner J. D-chiro-inositol--its functional role in insulin action and its deficit in insulin resistance. Int. J. Exp. Diabetes Res. 2002;3(1):47-60.

8. Kawa JM, Taylor CG, Przybylski R. Buckwheat concentrate reduces serum glucose in streptozotocin-diabetic rats. J. Agric. Food Chem. 2003;51(25):7287-91.

9. Yao Y, Shan F, Bian J, Chen F, Wang M, Ren G. D-chiro-inositol-enriched tartary buckwheat bran extract lowers the blood glucose level in KK-Ay mice. J. Agric. Food Chem. 2008;56(21):10027-31.

10. Fonteles MC, Almeida MQ, Larner J. Antihyperglycemic effects of 3-O-methyl-Dchiro-inositol and D-chiro-inositol associated with manganese in streptozotocin diabetic rats. Horm. Metab. Res. 2000;32(4):129-32.

11. Bates SH, Jones RB, Bailey CJ. Insulin-like effect of pinitol. Br. J. Pharmacol. 2000;130(8):1944-8.

12. Kim J-I, Kim JC, Kang M-J, Lee M-S, Kim J-J, Cha I-J. Effects of pinitol isolated from soybeans on glycaemic control and cardiovascular risk factors in Korean patients with type II diabetes mellitus: a randomized controlled study. Eur J Clin Nutr. 2005;59(3):456-8.

13. Kang M-J, Kim J-I, Yoon S-Y, Kim JC, Cha I-J. Pinitol from soybeans reduces 
postprandial blood glucose in patients with type 2 diabetes mellitus. J Med Food. 2006;9(2):182-6.

14. Narayanan CR, Joshi DD, Mujumdar AM, Dhekne VV. Pinitol - a new anti-diabetic compound from the leaves of Bougainvillea spectabilis. Current Science. 1987;56(3):139-41.

15. Majumder AL, Johnson MD, Henry SA. 1-myo-Inositol-1-phosphate synthase. Biochimica et Biophysica Acta (BBA) - Lipids and Lipid Metabolism. 1997;1348(1-2):24556.

16. Pak Y, Huang LC, Lilley KJ, Larner J. In vivo conversion of [3H]myoinositol to [3H]chiroinositol in rat tissues. J. Biol. Chem. 1992;267(24):16904-10.

17. Beemster P, Groenen P, Steegers-Theunissen R. Involvement of inositol in reproduction. Nutr. Rev. 2002;60(3):80-7.

18. Ortmeyer HK. Dietary myoinositol results in lower urine glucose and in lower postprandial plasma glucose in obese insulin resistant rhesus monkeys. Obes. Res. 1996;4(6):569-75.

19. Dang NT, Mukai R, Yoshida K-I, Ashida H. D-pinitol and myo-inositol stimulate translocation of glucose transporter 4 in skeletal muscle of C57BL/6 mice. Biosci. Biotechnol. Biochem. 2010;74(5):1062-7.

20. Yap A, Nishiumi S, Yoshida K-I, Ashida H. Rat L6 myotubes as an in vitro model system to study GLUT4-dependent glucose uptake stimulated by inositol derivatives. Cytotechnology. 2007;55(2-3):103-8.

21. Lundbaek K. Intravenous glucose tolerance as a tool in definition and diagnosis of diabetes mellitus. Br Med J. 1962;1(5291):1507-13.

22. González-Ortiz LJ, Martínez-Abundis E, González-Ortiz M. A new model to fit glucose concentration during the insulin tolerance test improving the predictive capability to estimate insulin sensitivity. Nutr Metab Cardiovasc Dis. 2006;16(1):78-9.

23. Etherton TD, Thompson EH, Allen CE. Improved techniques for studies of adipocyte cellularity and metabolism. J. Lipid Res. 1977;18(4):552-7.

24. Labarca C, Paigen K. A simple, rapid, and sensitive DNA assay procedure. Anal. Biochem. 1980;102(2):344-52.

25. Zarrouki B, Pillon NJ, Kalbacher E, Soula HA, Nia N'Jomen G, Grand L, et al. Cirsimarin, a potent antilipogenic flavonoid, decreases fat deposition in mice intra-abdominal adipose tissue. Int J Obes (Lond). 2010;34(11):1566-75.

26. Folch J, Lees M, Sloane Stanley GH. A simple method for the isolation and purification of total lipides from animal tissues. J. Biol. Chem. 1957;226(1):497-509.

27. Koracevic D, Koracevic G, Djordjevic V, Andrejevic S, Cosic V. Method for the measurement of antioxidant activity in human fluids. J. Clin. Pathol. 2001;54(5):356-61. 
28. Larner J, Brautigan DL, Thorner MO. D-Chiro-Inositol Glycans in Insulin Signaling and Insulin Resistance. Mol Med. 2010;16(11-12):543-52.

29. Ortmeyer HK, Larner J, Hansen BC. Effects of D-chiroinositol added to a meal on plasma glucose and insulin in hyperinsulinemic rhesus monkeys. Obes. Res. 1995;3 Suppl 4:605S-608S.

30. Costantino D, Minozzi G, Minozzi E, Guaraldi C. Metabolic and hormonal effects of myo-inositol in women with polycystic ovary syndrome: a double-blind trial. Eur Rev Med Pharmacol Sci. 2009;13(2):105-10.

31. Clements Jr. RS, Vourganti B, Kuba T, Oh SJ, Darnell B. Dietary myo-inositol intake and peripheral nerve function in diabetic neuropathy. Metabolism. 1979;28(4, Supplement $1): 477-83$.

32. Farias VX, Macêdo FHP, Oquendo MB, Tomé AR, Báo SN, Cintra DOS, et al. Chronic treatment with D-chiro-inositol prevents autonomic and somatic neuropathy in STZinduced diabetic mice. Diabetes Obes Metab. 2011;13(3):243-50.

33. Maeba R, Hara H, Ishikawa H, Hayashi S, Yoshimura N, Kusano J, et al. Myo-inositol treatment increases serum plasmalogens and decreases small dense LDL, particularly in hyperlipidemic subjects with metabolic syndrome. J. Nutr. Sci. Vitaminol. 2008;54(3):196202.

34. Corrado F, D'Anna R, Di Vieste G, Giordano D, Pintaudi B, Santamaria A, et al. The effect of myoinositol supplementation on insulin resistance in patients with gestational diabetes. Diabet. Med. 2011;28(8):972-5.

35. Larner J, Allan G, Kessler C, Reamer P, Gunn R, Huang LC. Phosphoinositol glycan derived mediators and insulin resistance. Prospects for diagnosis and therapy. J Basic Clin Physiol Pharmacol. 1998;9(2-4):127-37.

36. Ortmeyer HK, Bodkin NL, Hansen BC, Larner J. In vivo D-chiroinositol activates skeletal muscle glycogen synthase and inactivates glycogen phosphorylase in rhesus monkeys. The Journal of Nutritional Biochemistry. 1995;6(9):499-503.

37. Machicao F, Mushack J, Seffer E, Ermel B, Häring HU. Mannose, glucosamine and inositol monophosphate inhibit the effects of insulin on lipogenesis. Further evidence for a role for inositol phosphate-oligosaccharides in insulin action. Biochem. J. 1990;266(3):90916.

38. Hecht M-L, Tsai Y-H, Liu X, Wolfrum C, Seeberger PH. Synthetic inositol phosphoglycans related to GPI lack insulin-mimetic activity. ACS Chem. Biol. 2010;5(11):1075-86.

39. Bogardus C, Lillioja S, Mott DM, Hollenbeck C, Reaven G. Relationship between degree of obesity and in vivo insulin action in man. Am. J. Physiol. 1985;248(3 Pt 1):E28691. 
40. Coon PJ, Rogus EM, Drinkwater D, Muller DC, Goldberg AP. Role of body fat distribution in the decline in insulin sensitivity and glucose tolerance with age. Journal of Clinical Endocrinology \& Metabolism. 1992;75(4):1125-32.

41. Carey DG, Jenkins AB, Campbell LV, Freund J, Chisholm DJ. Abdominal fat and insulin resistance in normal and overweight women: Direct measurements reveal a strong relationship in subjects at both low and high risk of NIDDM. Diabetes. 1996;45(5):633-8.

42. Gastaldelli A, Miyazaki Y, Pettiti M, Matsuda M, Mahankali S, Santini E, et al. Metabolic Effects of Visceral Fat Accumulation in Type 2 Diabetes. Journal of Clinical Endocrinology \& Metabolism. 2002;87(11):5098-103.

43. Gabriely I, Ma XH, Yang XM, Atzmon G, Rajala MW, Berg AH, et al. Removal of Visceral Fat Prevents Insulin Resistance and Glucose Intolerance of Aging. Diabetes. 2002;51(10):2951-8.

44. Mohamed-Ali V, Pinkney JH, Coppack SW. Adipose tissue as an endocrine and paracrine organ. Int. J. Obes. Relat. Metab. Disord. 1998;22(12):1145-58.

45. Wisse BE. The inflammatory syndrome: the role of adipose tissue cytokines in metabolic disorders linked to obesity. J. Am. Soc. Nephrol. 2004;15(11):2792-800.

46. Trayhurn P, Wood IS. Adipokines: inflammation and the pleiotropic role of white adipose tissue. Br. J. Nutr. 2004;92(3):347-55.

47. Ferrannini E, Barrett EJ, Bevilacqua S, DeFronzo RA. Effect of fatty acids on glucose production and utilization in man. J. Clin. Invest. 1983;72(5):1737-47.

48. Boden G, Chen X, Ruiz J, White JV, Rossetti L. Mechanisms of fatty acid-induced inhibition of glucose uptake. J. Clin. Invest. 1994;93(6):2438-46.

49. Furukawa S, Fujita T, Shimabukuro M, Iwaki M, Yamada Y, Nakajima Y, et al. Increased oxidative stress in obesity and its impact on metabolic syndrome. J. Clin. Invest. 2004;114(12):1752-61.

50. Velussi M, Cernigoi AM, De Monte A, Dapas F, Caffau C, Zilli M. Long-term (12 months) treatment with an anti-oxidant drug (silymarin) is effective on hyperinsulinemia, exogenous insulin need and malondialdehyde levels in cirrhotic diabetic patients. J. Hepatol. 1997;26(4):871-9.

51. Rudich A, Tirosh A, Potashnik R, Khamaisi M, Bashan N. Lipoic acid protects against oxidative stress induced impairment in insulin stimulation of protein kinase $\mathrm{B}$ and glucose transport in 3T3-L1 adipocytes. Diabetologia. 1999;42(8):949-57.

52. Paolisso G, Balbi V, Volpe C, Varricchio G, Gambardella A, Saccomanno F, et al. Metabolic benefits deriving from chronic vitamin $\mathrm{C}$ supplementation in aged non-insulin dependent diabetics. J Am Coll Nutr. 1995;14(4):387-92.

53. Bashan N, Kovsan J, Kachko I, Ovadia H, Rudich A. Positive and negative regulation of insulin signaling by reactive oxygen and nitrogen species. Physiol. Rev. 2009;89(1):27-71. 
54. Ansar H, Mazloom Z, Kazemi F, Hejazi N. Effect of alpha-lipoic acid on blood glucose, insulin resistance and glutathione peroxidase of type 2 diabetic patients. Saudi Med J. 2011;32(6):584-8.

55. Jiang W-D, Wu P, Kuang S-Y, Liu Y, Jiang J, Hu K, et al. Myo-inositol prevents copper-induced oxidative damage and changes in antioxidant capacity in various organs and the enterocytes of juvenile Jian carp (Cyprinus carpio var. Jian). Aquatic Toxicology (Amsterdam, Netherlands). 2011;105(3-4):543-51.

56. Graf E. Antioxidant functions of phytic acid. Free Radical Biology and Medicine. 1990;8:61-9.

57. Nascimento NRF, Lessa LMA, Kerntopf MR, Sousa CM, Alves RS, Queiroz MGR, et al. Inositols prevent and reverse endothelial dysfunction in diabetic rat and rabbit vasculature metabolically and by scavenging superoxide. Proc. Natl. Acad. Sci. U.S.A. 2006;103(1):21823.

58. Lam S, McWilliams A, leRiche J, MacAulay C, Wattenberg L, Szabo E. A Phase I Study of myo-Inositol for Lung Cancer Chemoprevention. Cancer Epidemiology Biomarkers \& Prevention. 2006;15(8):1526-31. 


\section{Figures legends}

Figure 1. Chronic treatment with myo-inositol (1.2 $\mathrm{mg}^{-g^{-1}}$ per day, ip) improved glucose tolerance and insulin sensitivity in mice. Glucose tolerance was explored using glucose tolerance test (GTT). A - Blood glucose level evolution after intraperitoneal administration of glucose $\left(1 \mathrm{~g} . \mathrm{kg}^{-1}\right.$ i.p) to fasting mice. B. Insulin plasma level at the hyperglycaemic phase (30 min after i.p. glucose injection) of the GTT. C. Plasma insulin concentration was measured after intraperitoneal administration of a non-glucose insulin secretagogue (Arginine, $1 \mathrm{~g}^{\mathrm{kg}}{ }^{-1}$ ). $£, \mathrm{P}<0.005$, difference from baseline level. Note that no difference was found to be significant between the 2 groups at $\mathrm{p}<0.05$ level D. Insulin sensitivity was explored using insulin tolerance test. Blood glucose level was measured after intraperitoneal injection of insulin $\left(0,3 \mathrm{UI} \cdot \mathrm{kg}^{-1}\right)$ to fasting mice. Insert - Plasmatic Glucose disappearance rate $\left(\mathrm{K}_{\mathrm{ITT}}\right)$ during the insulin tolerance test. Results are expressed as mean \pm SEM for $n=10$ mice in each group. ${ }^{*} \mathrm{p}<0,05,{ }^{*} \mathrm{p}<0,01$, significant difference between saline and myo-inositol treated mice.

Figure 2. Insulin sensitivity is negatively correlated with central white adipose tissue mass. $n=20$. Central WAT was calculated as the sum of the intra-abdominal WAT pad weights, namely retroperitoneal and parametrial WAT pads.

Figure 3. Myo-inositol potentiated insulin signalling in skeletal muscle. A-Immunoblotting study of in vivo insulin induced phosphorylation of PKB/Akt in gatrocnemius muscle of mice daily treated with myo-inositol or saline. B- Myo-inositol for $15 \mathrm{~min}$ potentiated insulin signalling in skeletal muscle ex vivo. Immunoblotting study of ex vivo insulin induced phosphorylation of $\mathrm{PKB} / \mathrm{Akt}$ in gatrocnemius muscle. Mouse gastrocnemius muscle were incubated for $15 \mathrm{~min}$ with $1 \mathrm{mM}$ myo-inositol, D-chiro-inositol or mannitol as a control and stimulated with insulin $(100 \mathrm{nM}, 15 \mathrm{~min})$. Note that myo-inositol but not $D$-chiro-inositol potentiated insulin induced serine- phosphorylation of PKB/Akt. Results are expressed as mean \pm SD for $n=3-5$ mice in each group. Different letters indicate a significant difference at the $\mathrm{p}<0.05$ level.

Figure 4. Chronic treatment with myo-inositol $\left(0.9 \mathrm{mg}^{-\mathrm{g}^{-1}}\right.$ per day, orally) reduces white adipose tissue accretion in mice. A- Respective weights of WAT depots for myo-inositol and control mice. Results are expressed as mean \pm SEM for $n=14$ mice per group. ${ }^{* *} \mathrm{p}<0.01$ 
and $* * * \mathrm{p}<0.005$. B- Total WAT mass relative to the body weight in myo-inositol and saline treated mice. C,D- Adipocytes volume frequency distribution. Individual measurements were performed on 12-14,000 adipocytes using osmium tetroxide - coulter counter procedure as described in Methods. Frequency distribution of adipocytes volumes for saline (dotted line) and myo-inositol (solid line) treated animals. Note that distribution of adipocyte volume was shifted leftward (ie. towards smaller volumes) in myo-inositol mice. In each group, adipocytes were pooled from 8-10 mice. E- lipolysis and F- lipogenesis measured on isolated adipocytes from saline myo-inositol treated mice (data are mean \pm SEM for $\mathrm{n}=5$ ). Abbreviations: ISO, isoproterenol ; WAT, white adipose tissue ; eWAT, epididymal WAT; rWAT, retroperitoneal WAT; scWAT, subcutaneous WAT.

Figure 5. Proposed mechanism of effects of chronic treatment with myo-inositol on insulin sensitivity in mice. Abbreviations: IPG, inositolphosphoglycans ; NEFA, nonesterified fatty acids ; PIPs, phosphorylated inositol-phospholipids (phosphoinositides) ; ROS, reactive oxygen species. 
Table 1:

Biometric data and tissue weights in mice treated for 15 days with saline or myoinositol (1.2 $\mathrm{mg}^{\mathrm{kg}} \mathrm{k}^{-1}$ per day, ip)

\begin{tabular}{lrrcl}
\hline & control & myo-inositol & change & p-value \\
\hline Biometric data & & & & \\
BW, g & $31.7 \pm 0.7$ & $31.8 \pm 1.0$ & $0 \%$ & 0.963 \\
Body length, cm & $10 \pm 0.1$ & $10.3 \pm 0.1$ & $+3 \%$ & 0.362 \\
Lee index & $316 \pm 3$ & $308 \pm 2$ & $-3 \%$ & $0.023 *$ \\
\hline Organ weights & & & & \\
Liver, mg/10 g BW & $394 \pm 24$ & $403 \pm 14$ & $+2 \%$ & 0.749 \\
Heart, mg/10 g BW & $49 \pm 2$ & $46 \pm 1$ & $-6 \%$ & 0.416 \\
Kidneys, mg/10 g BW & $114 \pm 4$ & $120 \pm 2$ & $+5 \%$ & 0.193 \\
Gastrocnemius, mg/10 g BW & $43 \pm 3$ & $45 \pm 2$ & $+5 \%$ & 0.589 \\
Tibialis, mg/10 g BW & $18 \pm 1$ & $19 \pm 1$ & $+5 \%$ & 0.605 \\
\hline White Adipose tissue weights & & & & \\
pWAT, mg/10g BW & $259 \pm 19$ & $160 \pm 23$ & $-38 \%$ & $0.003 * * *$ \\
rWAT, mg/10g BW & $37 \pm 4$ & $23 \pm 5$ & $-38 \%$ & $0.020 *$ \\
scWAT, mg/10g BW & $95 \pm 14$ & $77 \pm 7$ & $-19 \%$ & 0.269 \\
Total WAT, mg/10g BW & $391 \pm 15$ & $260 \pm 37$ & $-33 \%$ & $0.009 * *$ \\
\hline
\end{tabular}

Data are mean \pm SEM for $n=14$ in each group. Data were compared using Student $t$ test and when appropriated Welch correction for variance inhomogeneity. Differences were considered significant at the $p<0.05$ level. Abbreviations: BW, body weight ; WAT, white adipose tissue ; pWAT, parametrial WAT ; rWAT, retroperitoneal WAT ; ScWAT, subcutaneous WAT. 
Table 2:

Plasma and tissue analysis in mice treated for 15 days with saline or myo-inositol (1.2 mg. $\mathrm{kg}^{-1}$ per day, ip)

\begin{tabular}{|c|c|c|c|c|}
\hline & control & myo-inositol & change & p-value \\
\hline \multicolumn{5}{|l|}{ Plasma glucose } \\
\hline Fed glucose, mM & $7.34 \pm 0.26$ & $6.61 \pm 0.2$ & $-10 \%$ & $0.031 *$ \\
\hline Fasted glucose, mM & $4.33 \pm 0.28$ & $4.61 \pm 0.18$ & $+6 \%$ & 0.713 \\
\hline Fasted insulin, pM & $257.7 \pm 22.15$ & $227.8 \pm 23.2$ & $-11 \%$ & 0.996 \\
\hline HOMA-IR & $1.70 \pm 0.15$ & $1.74 \pm 0.19$ & $+2 \%$ & 0.895 \\
\hline \multicolumn{5}{|l|}{ Plasma adipokins } \\
\hline Leptin, ng/ml & $13.7 \pm 3.1$ & $5.1 \pm 1.4$ & $-63 \%$ & $0.02 *$ \\
\hline Adiponectin, $\mu \mathrm{g} / \mathrm{ml}$ & $24.5 \pm 1.0$ & $25.9 \pm 1.6$ & $+6 \%$ & 0.457 \\
\hline \multicolumn{5}{|l|}{ Plasma lipids } \\
\hline Triacylglycerols, mM & $1.31 \pm 0.17$ & $1.19 \pm 0.15$ & $-10 \%$ & 0.349 \\
\hline NEFA, mM & $0.54 \pm 0.02$ & $0.34 \pm 0.01$ & $-37 \%$ & $<0.001 * * *$ \\
\hline Total cholesterol, mM & $3.81 \pm 0.34$ & $3.26 \pm 0.27$ & $-16 \%$ & 0.293 \\
\hline \multicolumn{5}{|l|}{ Plasma redox status } \\
\hline $\begin{array}{l}\text { Antioxidant activity, mM eq } \\
\text { Uric acid }\end{array}$ & $0.49 \pm 0.03$ & $0.72 \pm 0.04$ & $+46 \%$ & $0.002 * * *$ \\
\hline \multicolumn{5}{|l|}{ Tissue lipid content } \\
\hline Liver lipids, mg/g & $47.8 \pm 3.0$ & $46.9 \pm 3.5$ & $-2 \%$ & 0.852 \\
\hline Muscle lipids, mg/g & $9.3 \pm 2.4$ & $9.0 \pm 1.9$ & $-3 \%$ & 0.935 \\
\hline
\end{tabular}

Data are mean \pm SEM for $n=10$-12 in each group. Data were compared using Student $t$ test and when appropriated Welch correction for variance inhomogeneity. Differences were considered significant at the $p<0.05$ level. Abbreviations: HOMA-IR, homeostasis model assessment of insulin-resistance ; NEFA, non esterified fatty acids. 
Table 3:

Biometric data and organ weights in mice fed for 15 days with myo-inositol (0.9 mg. kg ${ }^{-1}$ per day)

control myo-inositol change p-value

\section{Bometric data}

BW, g

$37.6 \pm 1.2 \quad 34.9 \pm 1.4 \quad-7 \%$

0.157

Body length, $\mathrm{cm}$

$10.6 \pm 0.1 \quad 10.4 \pm 0.2 \quad-2 \%$

0.279

Lee index

$316 \pm 3$

$314 \pm 4$

$-1 \%$

0.646

\section{Organ weights}

Liver, mg/10g BW

$\begin{array}{rlrlll}422 & \pm 10 & 437 & \pm 13 & +4 \% & 0.413 \\ 45 \pm 2 & 46 \pm 1 & +2 \% & 0.496 \\ 114 \pm 3 & 119 \pm 5 & +4 \% & 0.373 \\ 41 \pm 2 & 44 \pm 2 & +7 \% & 0.440 \\ 20 \pm 1 & 20 \pm 1 & 0 \% & 0.992\end{array}$

Heart, mg/10g BW

Kidneys, mg/10g BW

Gastrocnemius, mg/10g BW

$20 \pm 1$

$20 \pm 1$

0.992

Tibialis, mg/10g BW

\section{Adipose tissue weights}

Total WAT, mg/10g BW

$724 \pm 70$

$447 \pm 74$

$-38 \%$

0.014*

Data are mean \pm SEM for $n=10$ in each group. Data were compared using Student $t$ test and when appropriated Welch correction for variance inhomogeneity. Differences were considered significant at the $p<0.05$ level. Abbreviations: BW, body weight, WAT white adipose tissue, pWAT, parametrial WAT, rWAT, retroperitoneal WAT, scWAT, subcutaneous WAT. 
Table 4:

Cellularity of parametrial white adipose tissue in mice fed for 15 days with myoinositol (0.9 mg. $\mathrm{kg}^{-1}$ per day)

\begin{tabular}{lcccl}
\hline & \multicolumn{1}{c}{ control } & myo-inositol & change & p-value \\
\hline pWAT, mg & $830 \pm 48$ & $549 \pm 81$ & $-34 \%$ & $0.015^{*}$ \\
Cell diameter, $\mu \mathrm{m}$ & $69.0 \pm 2.0$ & $59.8 \pm 3.0$ & $-13 \%$ & $0.02^{*}$ \\
Cell weight, $\mathrm{ng}$ & $176.3 \pm 15.6$ & $117.8 \pm 19.0$ & $-33 \%$ & $0.03^{*}$ \\
Nb cells, $\times 10^{6}$ & $5.21 \pm 0.62$ & $5.29 \pm 1.23$ & $+2 \%$ & 0.950 \\
DNA content $\mu \mathrm{g} / \mathrm{pad}$ & $63.0 \pm 13.0$ & $53.4 \pm 10.1$ & $-15 \%$ & 0.568 \\
\hline
\end{tabular}

Data are mean \pm SEM for $n=9-10$ in each group. Data were compared using Student $t$ test and when appropriated Welch's correction for variance inhomogeneity. Differences were considered significant at the $p<0.05$ level. Abbreviation: pWAT parametrial white adipose tissue. 

Figure 1

A

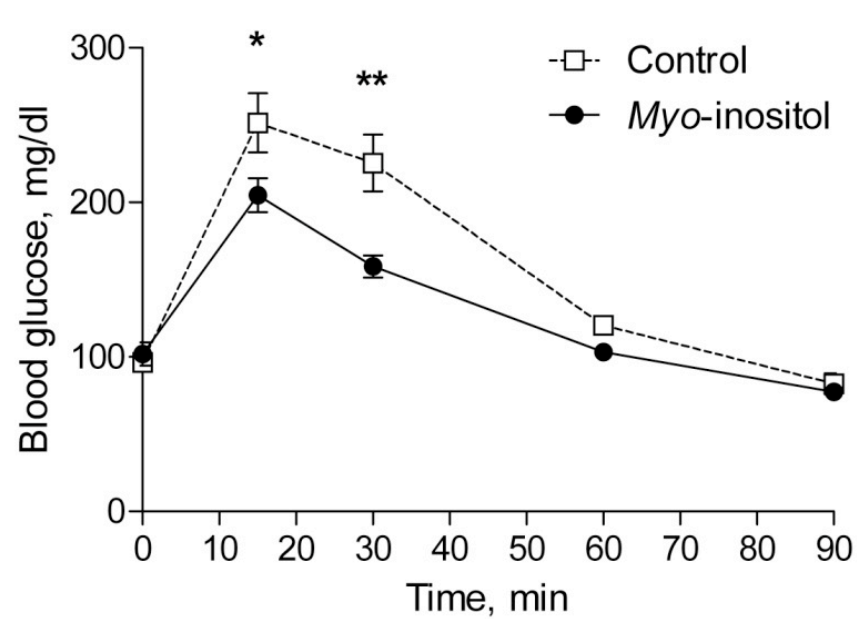

C

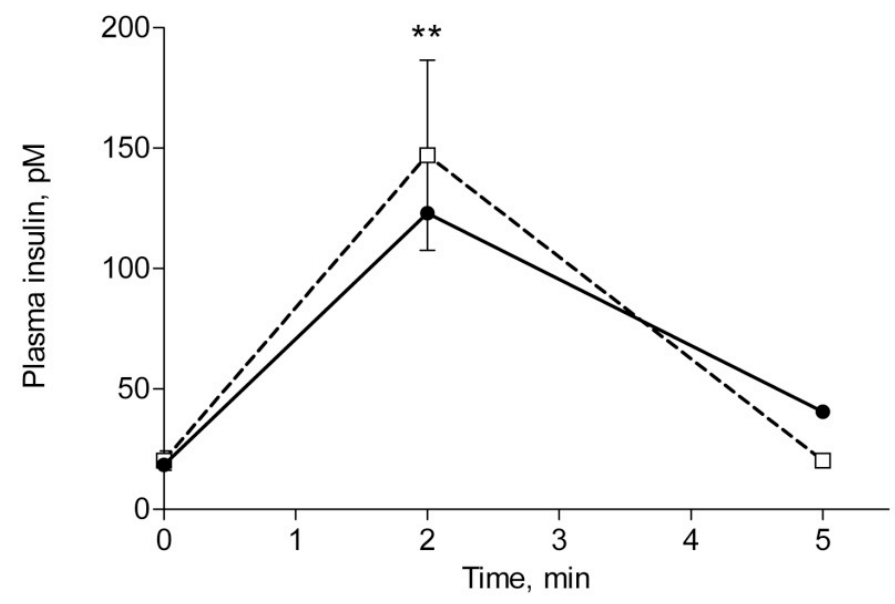

B

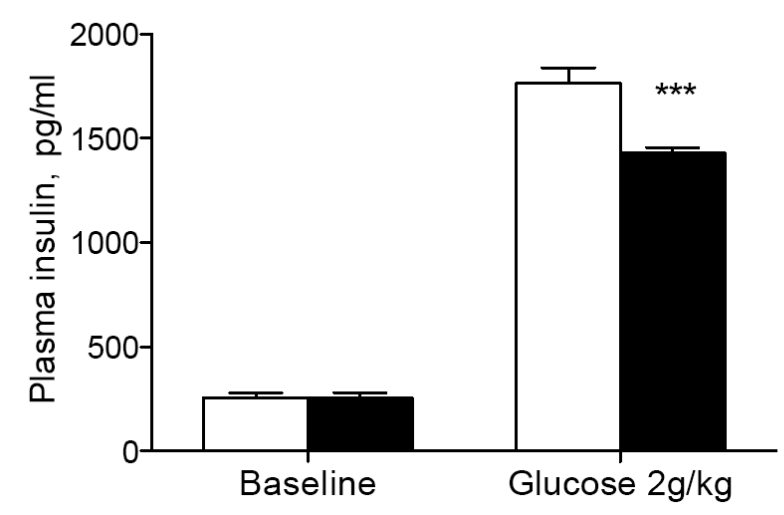

D

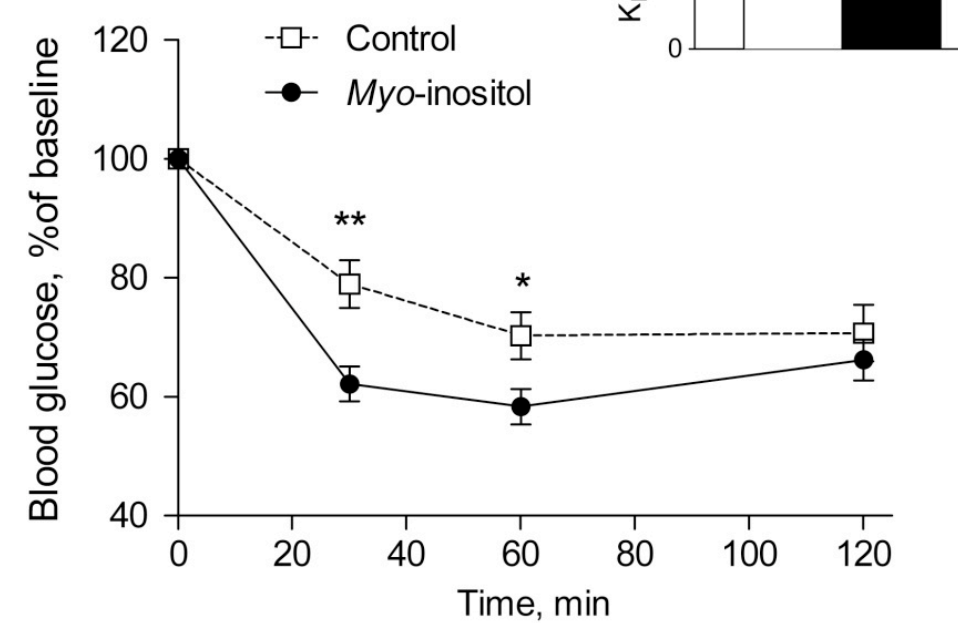


Figure 2

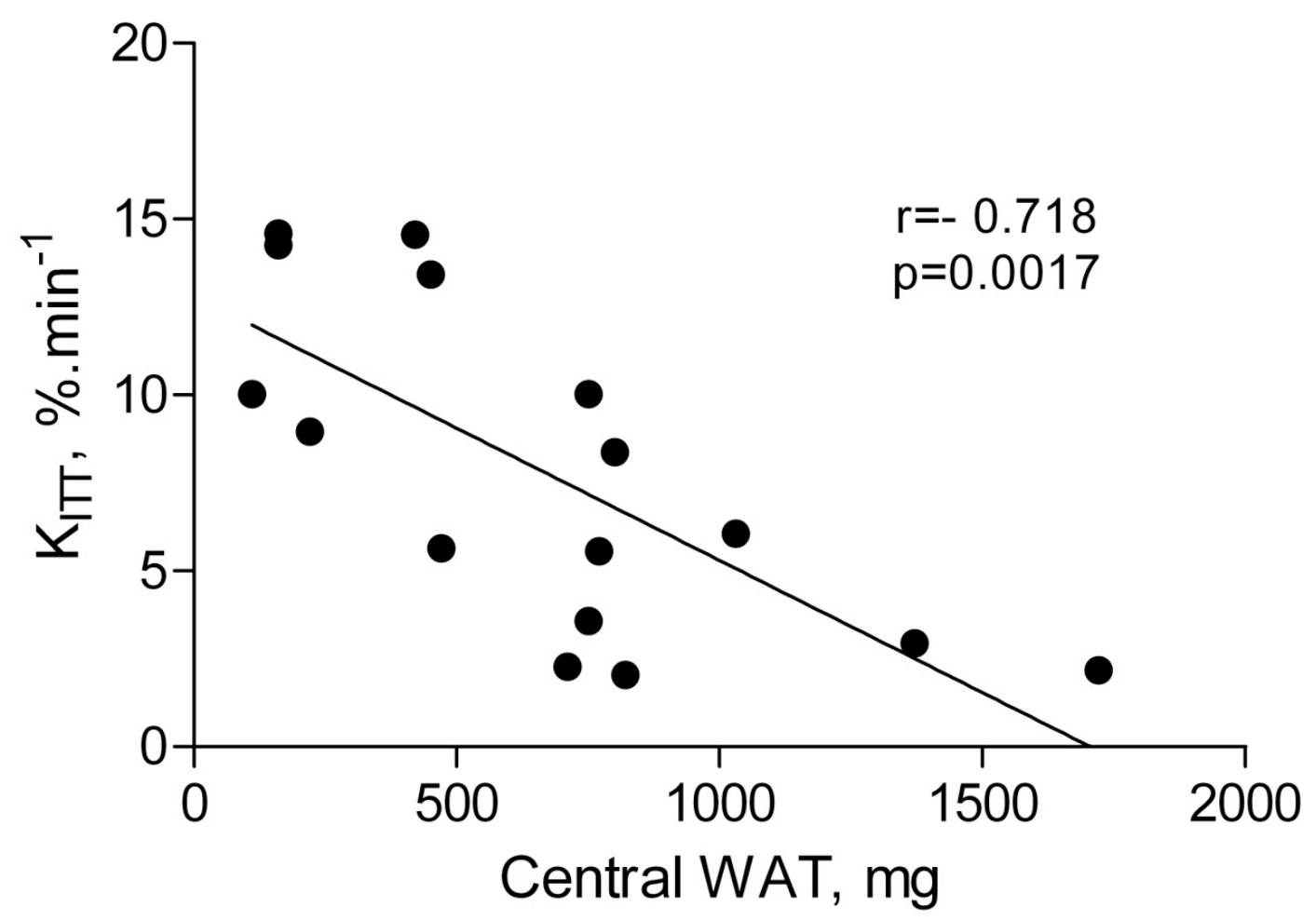




\section{Figure 3}

A
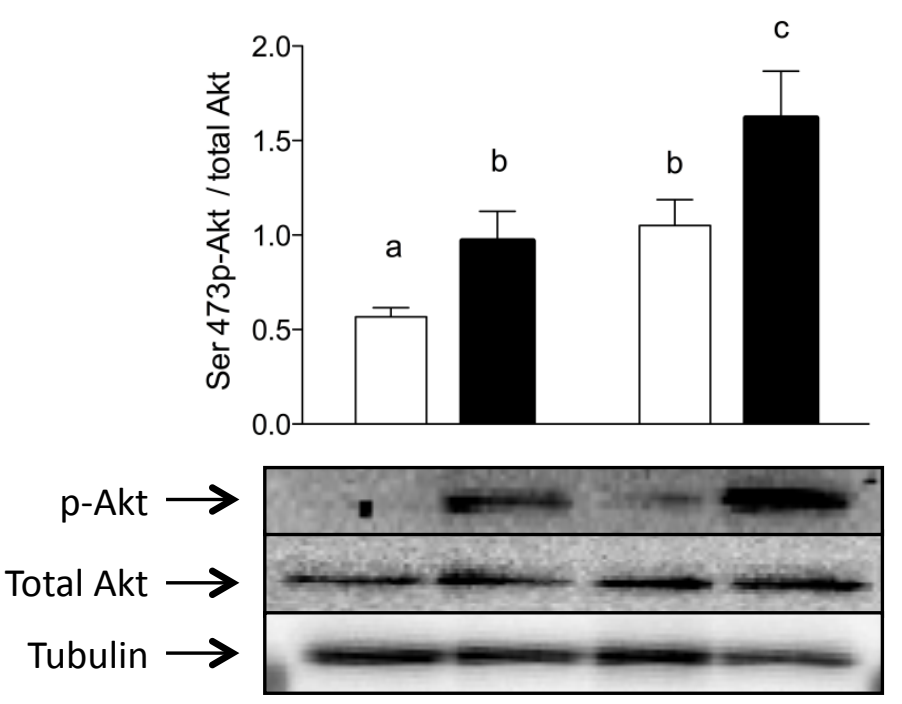

Myo-inosito

Insulin
$+$

$+$

\section{B}
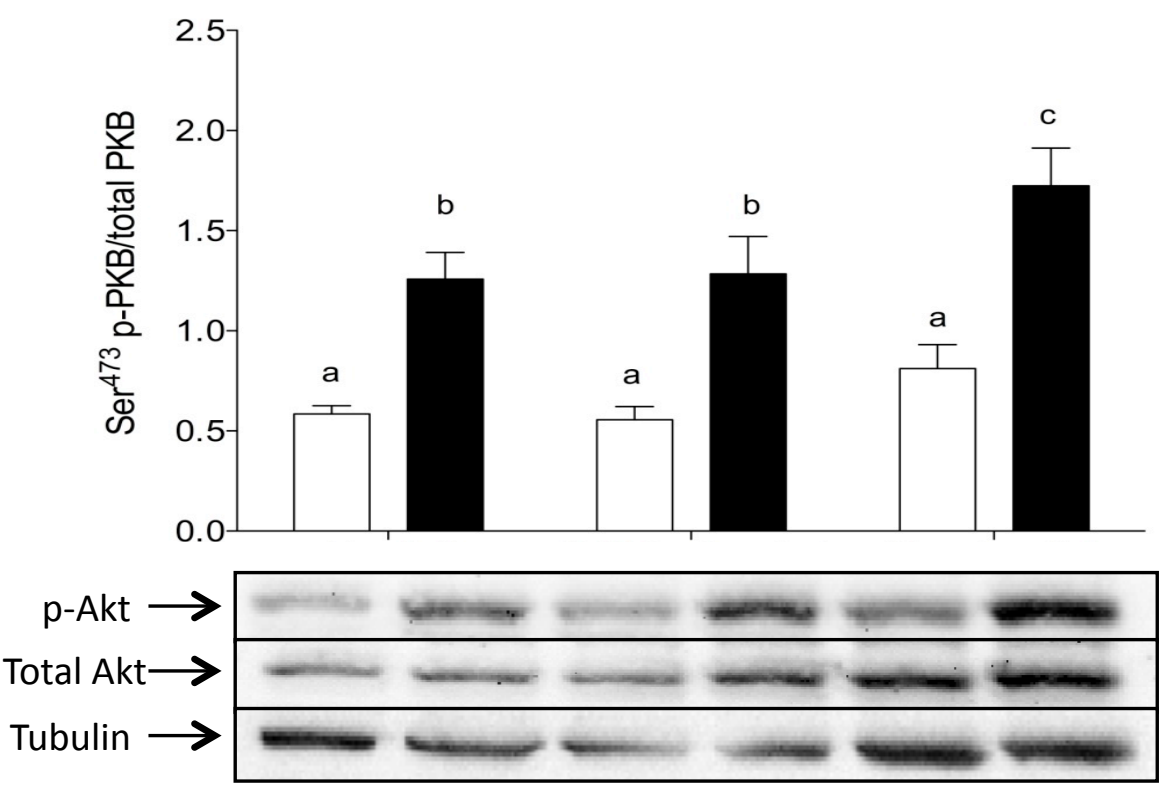

Mannitol

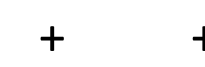

D-chiro-inositol

Myo-inositol

Insulin
$+$

$-$

-

$\begin{array}{lll}+ & - & - \\ - & + & + \\ + & - & +\end{array}$


Figure 4

A

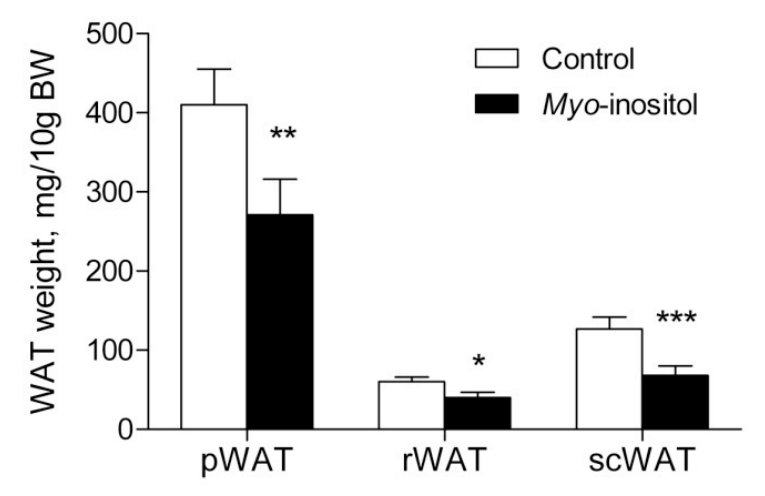

C

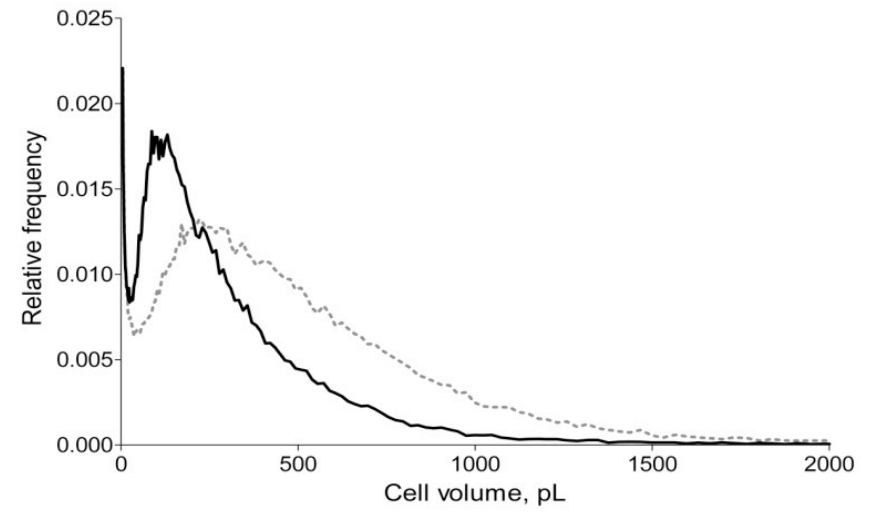

E

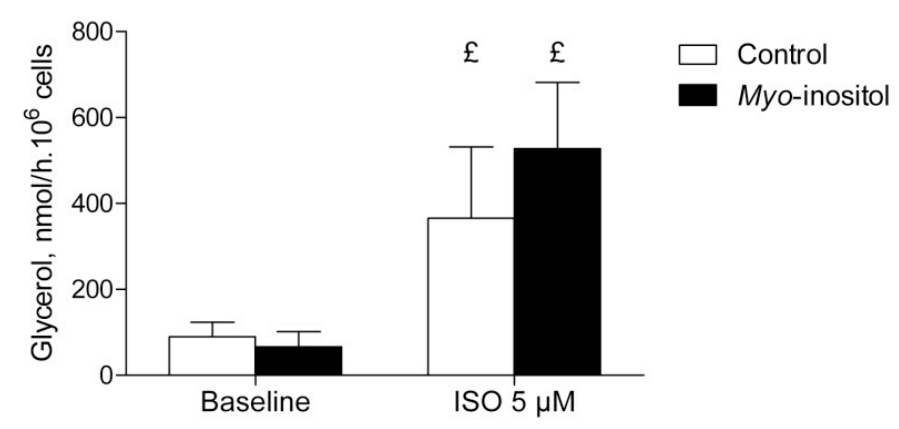

B

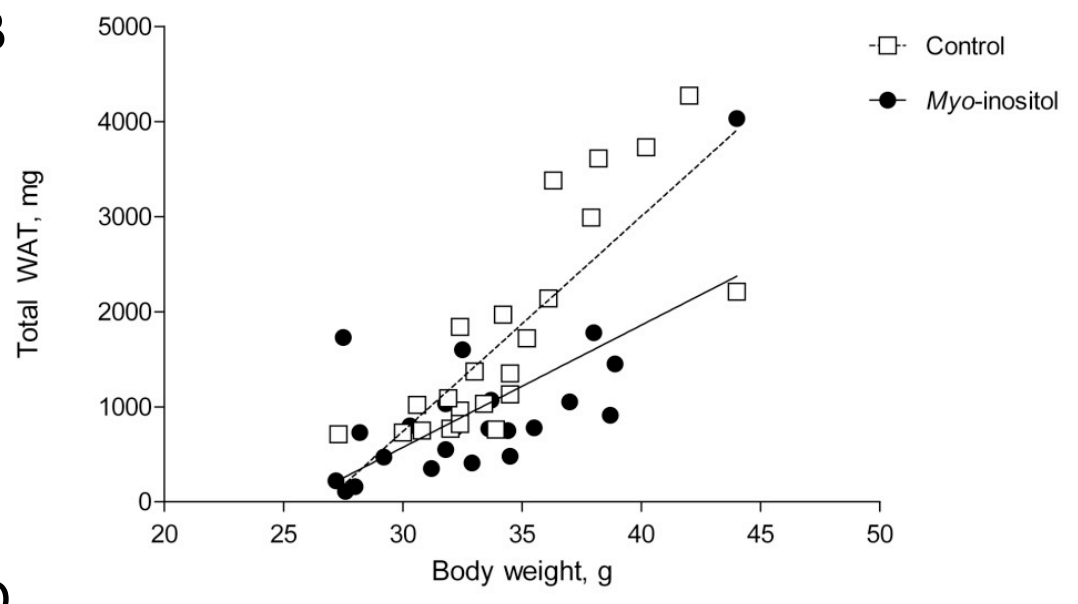

D

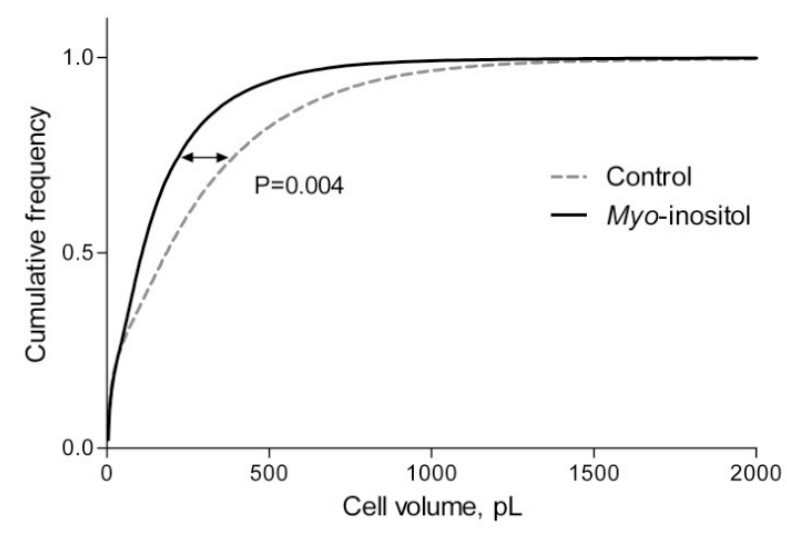

F

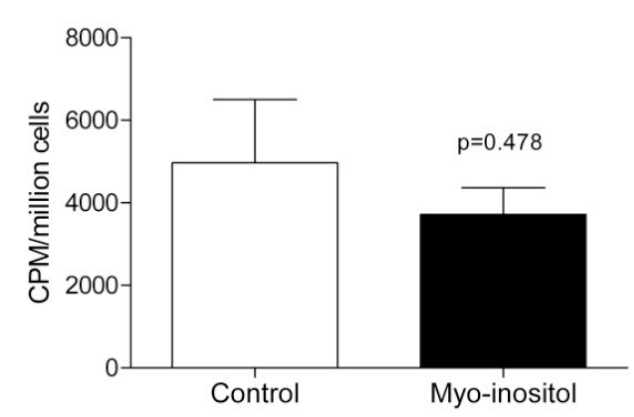


Figure 5

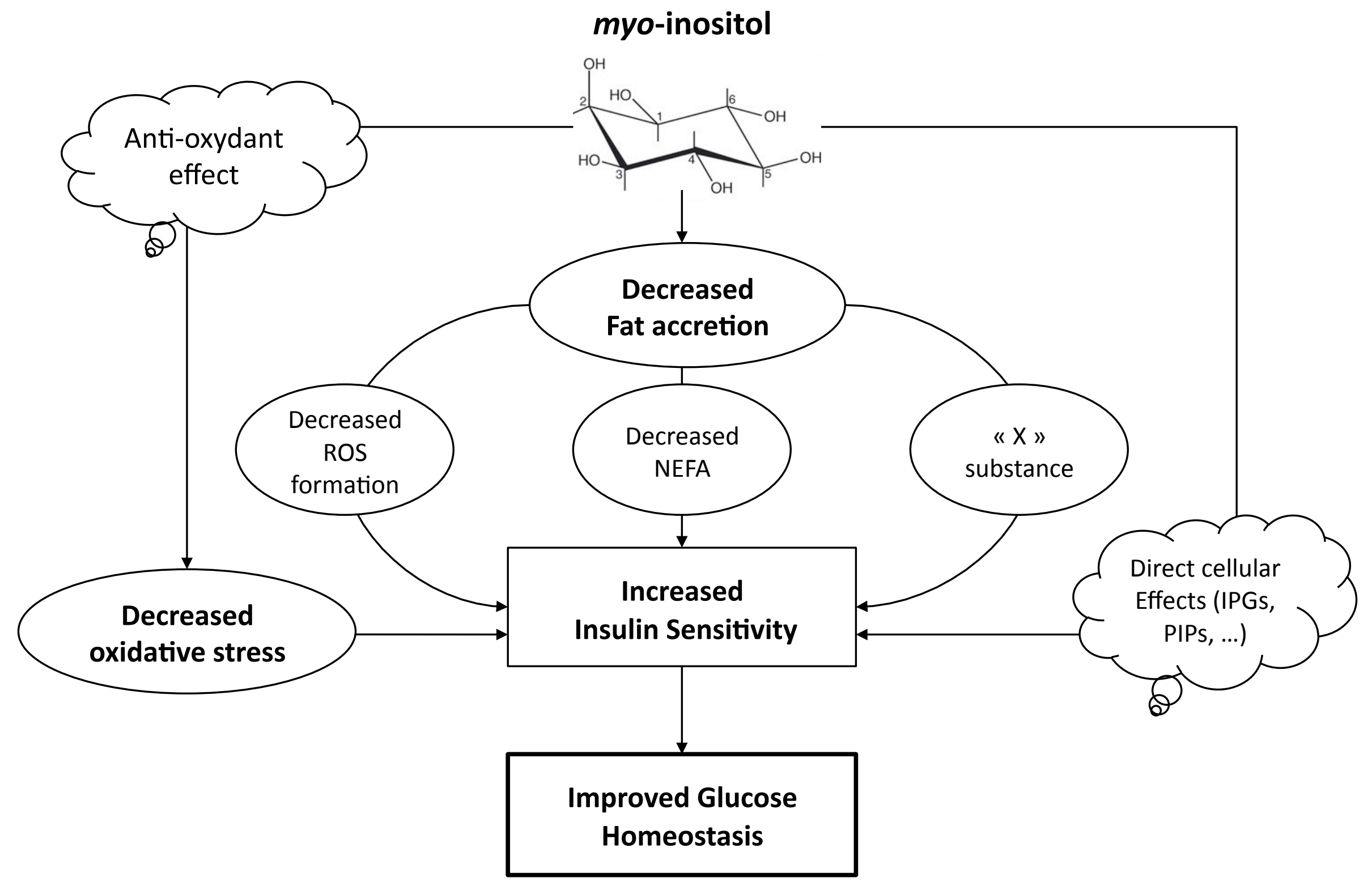




\section{Supplementary Figure 1}

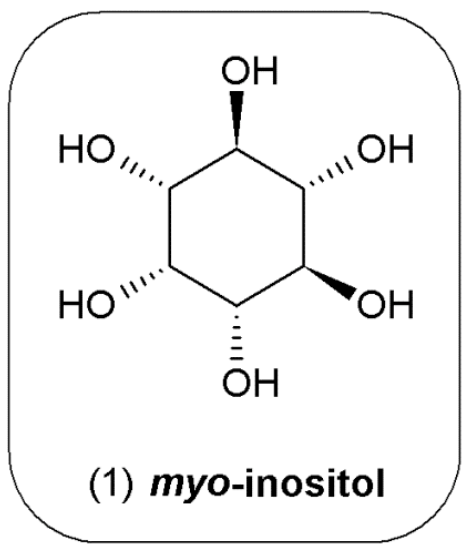<smiles>O[C@H]1[C@H](O)[C@H](O)[C@@H](O)[C@@H](O)[C@H]1O</smiles>

(2) scyllo-inositol<smiles>O[C@H]1[C@H](O)[C@H](O)[C@@H](O)[C@@H](O)[C@H]1O</smiles>

(3) muco-inositol<smiles>O[C@H]1[C@H](O)[C@H](O)[C@@H](O)[C@@H](O)[C@H]1O</smiles><smiles>O[C@H]1[C@H](O)[C@H](O)[C@H](O)[C@@H](O)[C@H]1O</smiles><smiles>O[C@H]1[C@H](O)[C@H](O)[C@@H](O)[C@@H](O)[C@H]1O</smiles>

(4) D-chiro-inositol<smiles>O[C@H]1[C@H](O)[C@H](O)[C@@H](O)[C@@H](O)[C@H]1O</smiles>

(7) allo-inositol

(5) L-chiro-inositol<smiles>O[C@H]1[C@H](O)[C@H](O)[C@@H](O)[C@@H](O)[C@H]1O</smiles>

(8) epi-inositol
(6) neo-inositol<smiles>O[C@H]1[C@H](O)[C@H](O)[C@@H](O)[C@@H](O)[C@H]1O</smiles>

(9) cis-inositol

Supplementary Figure 1. Structures of the nine stereoisomers of inositol. Myoinositol (framed) is the most common isomer of inositol in foodstuffs and animal tissues. 


\section{Supplementary Figure 2}

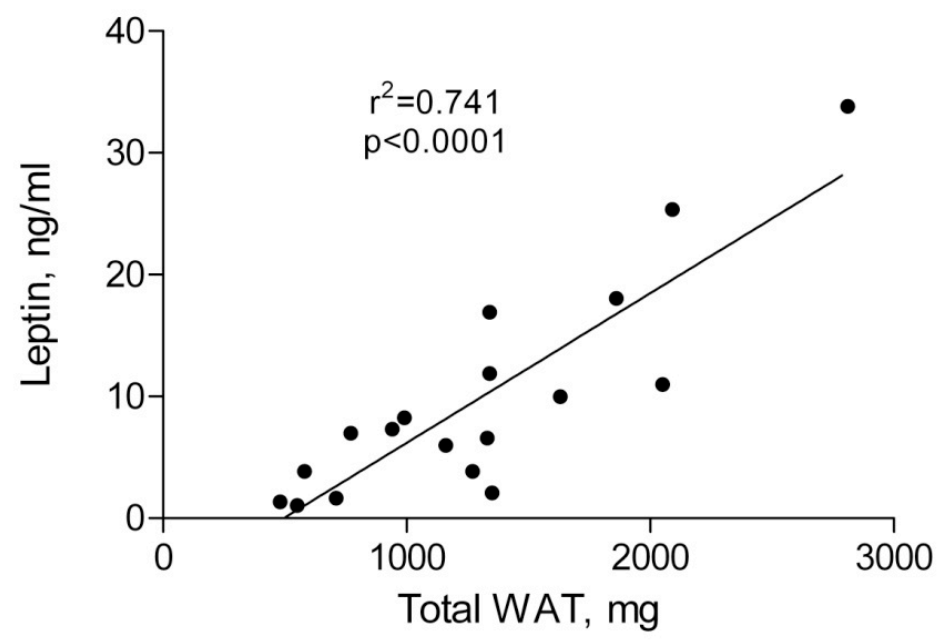

Supplementary Figure 2. plasma leptin concentration is correlated to white adipose tissue (WAT) mass in control and myo-inositol treated mice $(\mathrm{N}=19)$. 


\section{Supplementary Figure 3}

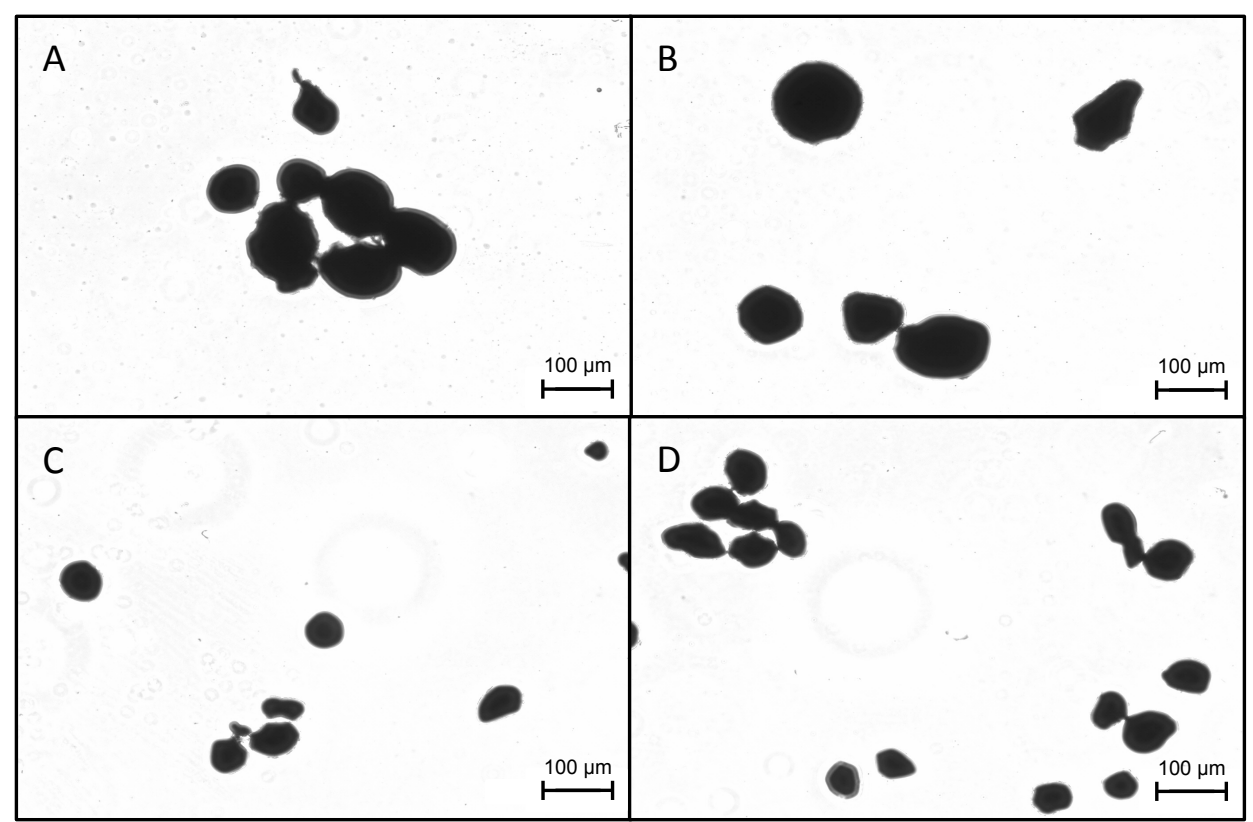

Supplementary Figure 3. Typical pictures of osmium tetroxide-fixed adipocytes from saline $(A, B)$ or myo-inositol treated mice $(\mathrm{C}, \mathrm{D})$. Adipocytes were isolated from epididymal fat pad as described in Methods. $(\times 100)$. Note that adipocytes from myo-inositol mice were smaller than those from control mice. 


\section{Supplementary Figure 4}

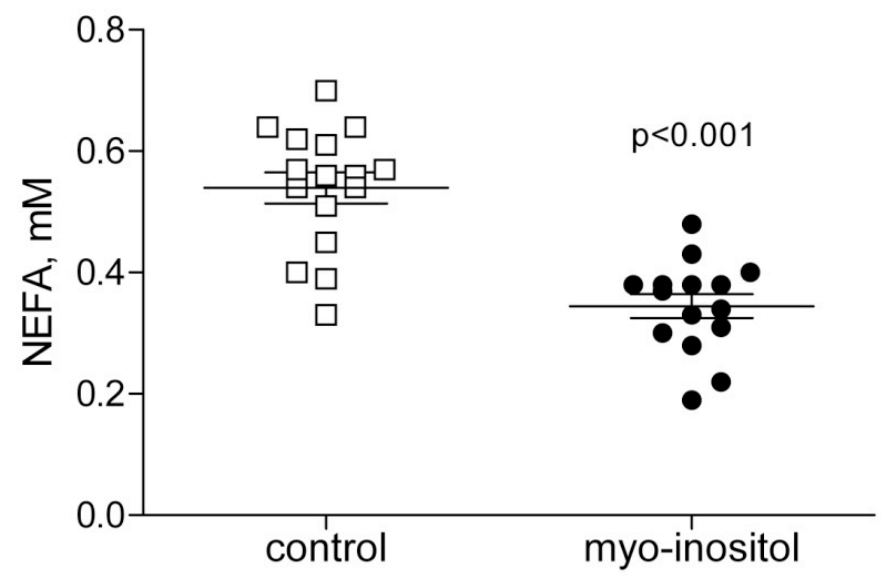

Supplementary Figure 4. Scattergram of plasma NEFA concentrations in control and myo-inositol-fed mice $(\mathrm{N}=14-16)$. NEFA were assayed in the fasting state as decribed in Methods. 